Research Article

\title{
Seismic Vibration Mitigation of Wind Turbine Tower Using Bi-Directional Tuned Mass Dampers
}

\author{
Wanrun Li $\mathbb{D},{ }^{1,2,3}$ Qing Zhang $\mathbb{D}^{3},{ }^{3}$ Zhou Yang $\mathbb{D}^{3},{ }^{3}$ Qingxin Zhu $\mathbb{D}^{4},{ }^{4}$ and Yongfeng $D u(\mathbb{D}, 1,2,3$ \\ ${ }^{1}$ Institute of Earthquake Protection and Disaster Mitigation, Lanzhou University of Technology, Lanzhou 730050, China \\ ${ }^{2}$ International Research Base of Seismic Mitigation and Isolation of Gansu Province, Lanzhou University of Technology, \\ Lanzhou 730050, China \\ ${ }^{3}$ School of Civil Engineering, Lanzhou University of Technology, Lanzhou 730050, China \\ ${ }^{4}$ Key Laboratory of C\&PC Structures of Ministry of Education, Southeast University, Nanjing 211189, China
}

Correspondence should be addressed to Wanrun Li; ce_wrli@163.com

Received 13 September 2020; Revised 14 October 2020; Accepted 13 November 2020; Published 2 December 2020

Academic Editor: Amr Elsonbaty

Copyright (c) 2020 Wanrun Li et al. This is an open access article distributed under the Creative Commons Attribution License, which permits unrestricted use, distribution, and reproduction in any medium, provided the original work is properly cited.

Wind turbines have been increasingly erected in earthquake regions to harvest abundant wind energy. However, the wind turbine tower is slender and lightly damping, which exhibits high susceptibility to earthquake-induced vibration. It is challenging to mitigate the seismic vibration of the tower. In this study, a bi-directional tuned mass damper (BTMD) is proposed to mitigate the seismic vibration of the wind turbine tower. Meanwhile, a lumped-mass finite element model (LFEM) and a coupled blade tower finite element model (CBFEM) are used to investigate the vibration mitigation performance of the BTMD. First, the BTMD and corresponding dynamic equilibrium equations are systemically introduced. Accordingly, the optimum stiffness and damping of the BTMD at different mass ratios are investigated. Then, the dynamic prosperities of the LFEM and CBFEM are compared. Subsequently, the seismic responses of the wind turbine with the BTMD are conducted using the LFEM and CBFEM. Meanwhile, the mitigation performances of the BTMD under uni- and bi-directional earthquakes are investigated. The displacement, acceleration, and bending moment of the wind turbine tower are analyzed in time domain and frequency domain. Note that the influential factors, including mass ratio and structural frequency, on the vibration mitigation performance of the BTMD are investigated. Results show that the proposed BTMD can significantly mitigate the peak values of the top displacement and bottom bending moment. However, the blade tower coupling effect and frequency variation of the tower would have influences on the mitigation efficiency of the BTMD. The results enable a better understanding of the seismic vibration mitigation of the wind turbine tower using tuned mass dampers.

\section{Introduction}

Wind generation overgrows with the merits of fine environment pollution, technology maturation, and sustainability. Numerous wind turbines have been developed in harsh environments and seismic hazard zones to harvest abundant wind energy. These tall and slender wind turbines are vulnerable to wind- and earthquake-induced vibrations, which can be devastating. Numerous vibration control techniques have been developed for building and bridge vibration mitigation, including passive tuned mass damper (PTMD) [1-6], active tuned mass damper (ATMD) $[7,8]$, semiactive control system [9-11], and hybrid control system [12, 13], which can provide references for the vibration mitigation of the wind turbine. Numerous researchers and engineers devote their attention to the vibration mitigation of wind turbines using enhanced building utilized vibration control devices. In the aspect of using TMD, Stewart and Lackner [14] examined the performance of tuned mass damper (TMD) on the vibration control of wind turbines, and the results demonstrated that the TMD could reduce tower fatigue load efficiently, particularly in side-to-side directions. Altay et al. [15] utilized TMD to mitigate the seismic-induced vibration of the wind turbine tower considering soil-structure interaction. The results showed that TMD could reduce resonant tower vibrations and improve the fatigue life of wind turbines effectively. Zhao et al. [16] 
investigated the vibration control effects of a TMD on the monopole offshore wind turbine tower subjected to wind-wave excitations and seismic excitations. The shaking table tests on a $1 / 13$-scaled test model equipped without or with bi-directional TMD, whose mass ratio and frequency ratio were properly designed, are conducted to verify the effectiveness of the bidirectional TMD. It concluded that TMD effectively weakens the dynamic responses of the monopole offshore wind turbine undergoing a variety of earthquake inputs and equivalent wind-wave loads, and the performance is highly dependent on the frequency contents of external excitations.

In addition, tuned liquid column damper (TLCD) and tuned liquid damper (TLD) are employed to mitigate the seismic vibration of wind turbines. Colwell and Basu [17] investigated the performance of the offshore wind turbine with TLCD under wind and wave loadings. It was found that the peak response reductions of the wind turbine with TLCD may be up to $55 \%$ of those the wind turbine without TLCD when it is subjected to wind and wave forces. Buckley et al. [18] employed a TLCD to reduce structural vibrations of a wind turbine tower while considering the interaction of the tower and the foundation soil. The efficiency of TLCDs was investigated numerically and experimentally. Results found that soil-structure interaction played a critical role in designing TLCD for wind turbine tower vibration control, and the optimal tuning of the TLCD may need readjustment over the lifespan of turbines. Hemmati et al. [19] conducted TLCD and TMD to study the vibration suppression in offshore wind turbine foundations. Their findings indicated that the standard deviation of the dynamic response could be significantly reduced by using all structural control devices. TMDs were more efficient in operational conditions, and TLCDs showed better performances in parked conditions. Dai et al. [20] studied the performance of the tuned liquid particle damper (TL-PD) on wind turbine vibration, which combines the tuned liquid damping and particle damping technology. The authors concluded that the structural dynamic response could be reduced effectively. Chen et al. [21] proposed a spherical tuned liquid damper (TLD) to reduce the earthquake-induced vibration of wind turbines and investigated its performance of controlling the structural vibration via a $1 / 20$-scale shaking table test. The authors found that the effectiveness of spherical TLDs did not increase linearly as the mass of water in containers and was influenced greatly by the frequency components of earthquake excitations. Zhang et al. [22] utilized real-time hybrid testing to evaluate full-scale tuned liquid dampers (TLDs) in controlling large wind turbine vibration. Van et al. [23] explored vibration isolation in wind turbine structures and proposed vibration isolators for turbine towers, which are mounted below the nacelle. The author demonstrated that implementing an isolation system may be beneficial to reduce certain key parameters of the wind turbine structural response.

As mentioned above, the vibration control system is installed at the location where the peak displacement appears, which is the most effective way to reduce windinduced vibrations. However, many wind farms are constructed in the areas with high seismic potentials. Seismic load can be another vibration source during their lifetimes in these regions [24]. The higher vibration modes might also be excited as the seismic energy has a broader frequency range, which can further contribute to or even govern the structural responses of the wind turbine. In this case, using a single TMD in the nacelle and tuning it to the fundamental vibration frequency of the tower are not effective, and the damper should be installed at the location where the largest displacement occurs. Researchers employ multiple TMD to mitigate wind turbine tower vibration. Zuo et al. [25] proposed multiple TMDs (MTMDs) to control vibrations of the fundamental and higher modes of offshore wind turbine tower under multiple hazards, and the validity was examined numerically. Hussan et al. [26] installed MTMD at the top and base of the turbine tower corresponding to the mode shapes of the structure to mitigate the first two vibrational modes of jacket-support offshore wind turbine tower under seismic excitations. Gaur et al. [27] compared the control efficiency of the single tuned mass damper (STMD) and distributed multiple tuned mass dampers (d-MTMDs) on the wind turbine with consideration of blade coupling and soil-structure interaction (SSI).

Through the above research works, the same conclusion is obtained where the MTMDs are suitable for multimode control, while STMD is useful for suppressing a single vibration mode. However, due to the limited spare space in the nacelle for additional TMD mass, the control efficiency of the TMD is restrained. Hence, lightweight and small volume are more feasible for the wind turbine. Some scholars proposed an inerter-based TMD system to reduce the physical mass of a conventional TMD system. An inerter device can transform the linear motion into the high-speed rotational motion, which can significantly amplify the physical mass of the system. Hu et al. [28] proposed an inerter-based structural control system, consisting of a parallel connection of a spring, a damper, and an inerter-based network. Three different configurations were employed to constitute the inerter-based network. The effectiveness of the proposed method on controlling the dynamic responses of a barge-type floating offshore wind turbine was investigated numerically by the modified nonlinear FAST-SC code. Results showed that the proposed novel system could effectively mitigate the displacement at the top of the tower while having similar TMD working space as the system without inerter. Zhang et al. [29] conducted the tuned parallel inerter mass system (TPIMS), consisting of a tuned mass, a spring, and parallel inerter subsystem, to mitigate the seismic response of the wind turbine tower. The results found that TPIMS can effectively reduce the seismic response of the wind turbine tower. Furthermore, a much smaller tuned mass of the TPIMS can realize the same target displacement reduction compared with that of the traditional tuned mass dampers done. Although inerter-based structural control system has been verified effectively on wind turbine vibration mitigation, it is in the initial stage and needs to be further studied, such as the working space and parameters of optimal design. 
Numerous researches are also explored to use the ATMD and semiactive TMD to control the vibration of the wind turbine. Brodersen et al. [30] employed an ATMD, which is controlled by the feedback of the tower top displacement and the relative velocity of the damper mass to reduce the tower vibration. They concluded that the ATMD provided a considerable decrease in the frequency response, and it was also superior in reducing vibration in transient conditions compared to passive TMD. Sun [31] introduced a semiactive TMD with tuneable natural frequency and damping ratio to control the dynamic response of monopole offshore wind turbines subjected to multihazards consisting of wind, wave, and earthquake. Results showed that, considering the soil effects, damage, and multihazards, the STMD was consistently effective in controlling the response of the tower, whereas the passive TMD may become completely ineffective and induce a potential threat to the structure. Results showed that active structural control could provide better performance than passive control. However, passive structural control has its unique advantages, such as high reliability and low cost, which is particularly essential for offshore wind turbines due to their long lifespan.

Most of the aforementioned references focused on unidirectional response (fore-aft motion) mitigation, while the real wind turbines suffer from bi-directional vibration (foreaft and side-side) due to wind misalignment, vortex-induced crosswind vibration, and other misaligned loadings, such as earthquakes. The bi-directional vibration control of the wind turbine is relatively scarce. Sun and Jahangiri [32] proposed a three-dimensional pendulum tuned mass damper $(3 \mathrm{~d}$ PTMD) to mitigate the tower and nacelle dynamic response in the fore-aft and side-side directions. The authors found that the proposed 3d-PTMD was more effective than that of the dual linear TMDs in mitigating the bi-directional vibration of the offshore wind turbine under misaligned loading considering some uncertainty from soil effects. Tong et al. [33] employed two linear TMDs, which shared the same mass component and were installed in both the fore-aft and sideto-side directions of the tower, to reduce the vibration of the tower. The infinite-dimensional model of the monopile wind turbine tower-TMD system was made. The parameters of the TMD were optimized by minimizing the frequency-limited $\mathrm{H} 2$-norm of the transfer function matrix. It is concluded that the performance of the optimal TMDs was similar to that of [14]. Although the preliminary exploring works have been done and some researchers have reviewed astate-of-the-art current vibration control techniques and their applications to wind turbines $[34,35]$, there is still great progress needed to the technology maturation and practical application.
In this study, a bi-directional tuned mass damper (BTMD) is proposed to mitigate the seismic vibration of the wind turbine tower. Meanwhile, a lumped-mass finite element model (LFEM) and a coupled blade tower finite element model (CBFEM) are used to investigate the vibration mitigation performance of the BTMD. First, the BTMD and corresponding dynamic equilibrium equations are systemically introduced. Accordingly, the optimum stiffness and damping of TMD at different mass ratios are investigated. Then, the dynamic prosperities of LFEM and CBFEM are compared. Afterward, the seismic responses of the wind turbine with the BTMD are conducted using the LFEM and CBFEM. Meanwhile, the mitigation performances of the BTMD under uni- and bi-directional earthquakes are investigated. The displacement, acceleration, and bending moment of wind turbine towers are analyzed in time-domain and frequency-domain. Note that the influential factors, including mass ratio and structural frequency variation, on the vibration mitigation performance are investigated. Results show that the proposed BTMD can significantly mitigate the peak values of the top displacement and bottom bending moment. However, the blade tower coupling effect and frequency variation would influence the mitigation efficiency of the BTMD.

\section{Bi-Directional Tuned Mass Dampers (BTMDs)}

2.1. The BTMD Model. The proposed BTMD is shown in Figure 1, which consists of a mass block, two sets of springdamping systems, slide rails, and two sets of rollers. The slide rail is set on the inside wall of the device, and the mass block can move along the two directions slide rail independently. The spring-damping system dissipates the kinetic energy of the mass block. Two sets of mutually perpendicular rollers are arranged at the bottom of the device to reduce the friction force between the mass block and bottom plate. The configuration of the BTMD is streamlined, which does not disturb the airflow characteristics of the wind field. The BTMD is installed on the roof of the nacelle. The parameters of the BTMD, including the spring stiffness and the mass of the block, are tuned according to the frequency of controlled structures.

2.2. The Mechanical Model. The mechanical model of the BTMD-equipped wind turbine is shown in Figure 2, and the corresponding equation of motion is written as equation (1). Note that the coupling effect between two directional vibrations is ignored.

$$
\left[\begin{array}{cc}
M & 0 \\
0 & m
\end{array}\right]\left[\ddot{x}_{M} \ddot{x}_{d}\right]+\left[\begin{array}{cc}
C+c & -c \\
-c & c
\end{array}\right]\left[\begin{array}{c}
\dot{x}_{M} \\
\dot{x}_{d}
\end{array}\right]+\left[\begin{array}{cc}
K+k & -k \\
-k & k
\end{array}\right]\left[\begin{array}{c}
x_{M} \\
x_{d}
\end{array}\right]=\left[\begin{array}{c}
P(t) \\
0
\end{array}\right],
$$

where $x_{M}$ and $x_{d}$ are the displacements of wind turbine and mass block of the BTMD, respectively; $M$ and $m$ are the mass of the wind turbine and mass block, respectively; $C$ and $c$ are the damping of the wind turbine and BTMD, respectively; $K$ and $k$ are the stiffness of the wind turbine and TMD, respectively; $P(t)$ is the load applied to the wind turbine. 


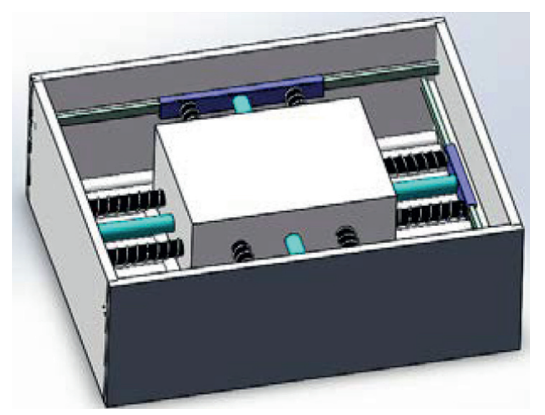

(a)

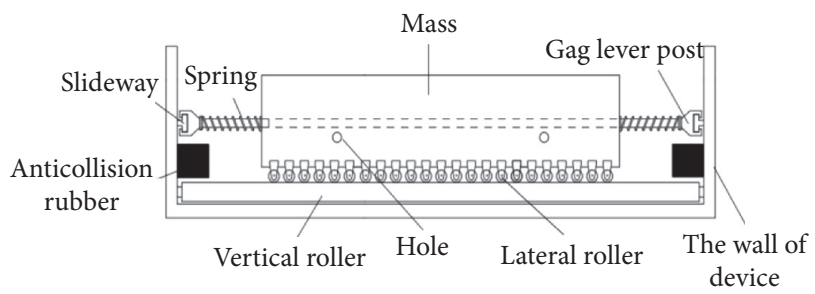

(c)

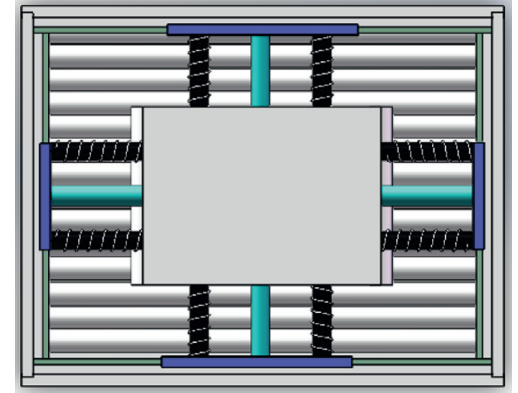

(b)

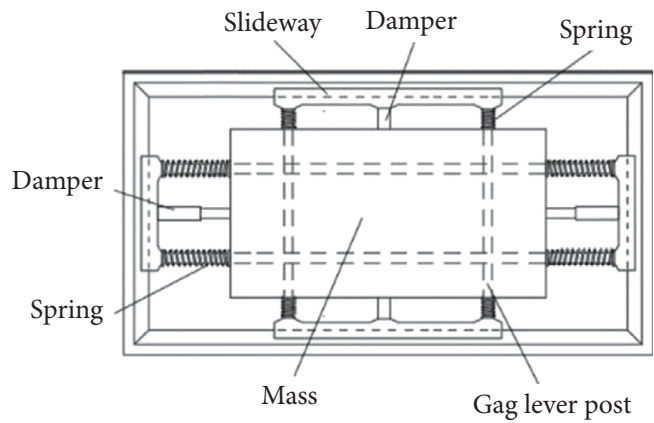

(d)

Figure 1: The BTMD model. (a) The diagram of the BTMD. (b) The planform of the BTMD. (c) Lateral view of the BTMD. (d) Aerial view of the BTMD.

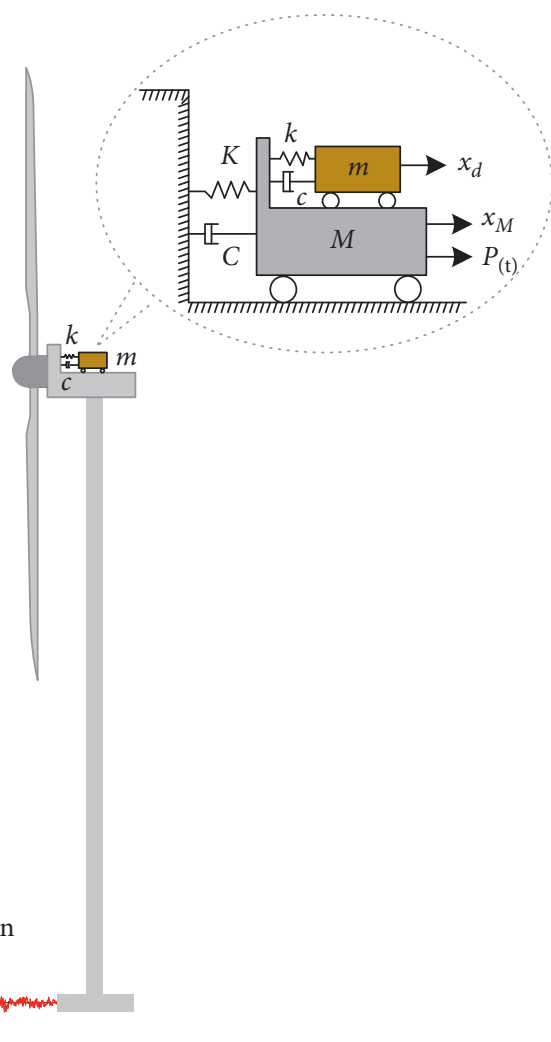

FIgURe 2: Diagram of the wind turbine with TMD system. 
Accordingly, the displacement amplification factor, $R$, can be calculated using

$$
R=\sqrt{\frac{\left(\alpha^{2}-\beta^{2}\right)^{2}+(2 \zeta \alpha \beta)^{2}}{\left[\left(\alpha^{2}-\beta^{2}\right)\left(1-\beta^{2}\right)-\alpha^{2} \beta^{2} \mu\right]^{2}+(2 \zeta \alpha \beta)^{2}\left(1-\beta^{2}-\mu \beta^{2}\right)^{2}}},
$$

where $\alpha$ is the ratio of the natural frequency of the BTMD to that of the wind turbine, $\beta$ is the ratio of the frequency of external load to the natural frequency of wind turbine, $\mu$ is the mass ratio of BTMD to that of the wind turbine, and $\zeta$ is the damping ratio of the wind turbine. The amplification factor, $R$, reaches the minimum value when $\alpha, \mu$, and $\zeta$ satisfy the following equations:

$$
\begin{aligned}
& \alpha_{\mathrm{opt}}=\frac{1}{1+\mu}, \\
& \xi_{\mathrm{opt}}=\sqrt{\frac{3 \mu}{8(1+\mu)}},
\end{aligned}
$$

where $\alpha_{\mathrm{opt}}$ and $\xi_{\mathrm{opt}}$ represent the optimal frequency ratio and damping ratio of the BTMD, respectively. Accordingly, the relationships between BTMD parameters and the amplification factor are shown in Figure 3. Note that five mass ratios, varying from 0.01 to 0.05 , are utilized to investigate the influence of the mass ratio.

According to Figure 3, the amplification factor decreases with the increase of mass ratio. Meanwhile, the peak amplification ratio is significantly suppressed due to the BTMD. Hence, the optimal mass, stiffness, and damping of the BTMD can be calculated using the following equations:

$$
\begin{aligned}
m_{d} & =\mu m_{1}, \\
k_{\mathrm{opt}} & =\alpha_{\mathrm{opt}}^{2} \omega_{1}^{2} m_{d}, \\
c_{\mathrm{opt}} & =2 \xi_{\mathrm{opt}} \alpha_{\mathrm{opt}} \omega_{1} m_{d},
\end{aligned}
$$

where $m_{d}, k_{\mathrm{opt}}$, and $c_{\mathrm{opt}}$ are the optimal mass, stiffness, and damping of the BTMD, respectively, $\omega_{1}$ is the first-order natural frequency of the wind turbine, and $m_{1}$ is the firstorder modal mass of the wind turbine.

\section{The Wind Turbine Model}

3.1. Description of the Wind Turbine. A $2.5 \mathrm{MW}$ three-blade horizontal wind turbine, which is commonly constructed in the Western of China, is shown in Figure 4. The tower is a cylindrical hollow single steel tube with the wheel hub height of $98.12 \mathrm{~m}$. The diameter and thickness of the tower vary across the height. The diameter and thickness of the bottom tower are $3.9 \mathrm{~m}$ and $67 \mathrm{~mm}$, respectively, while the diameter and thickness of the top tower are $2.55 \mathrm{~m}$ and $20 \mathrm{~mm}$, respectively. The nacelle is mounted on the tower top where the rotor shaft holding turbine blades is connected. The nacelle height and weight are $3.2 \mathrm{~m}$ and 52 tons, respectively. The sum weight of the blade and hub is 31.155 tons.

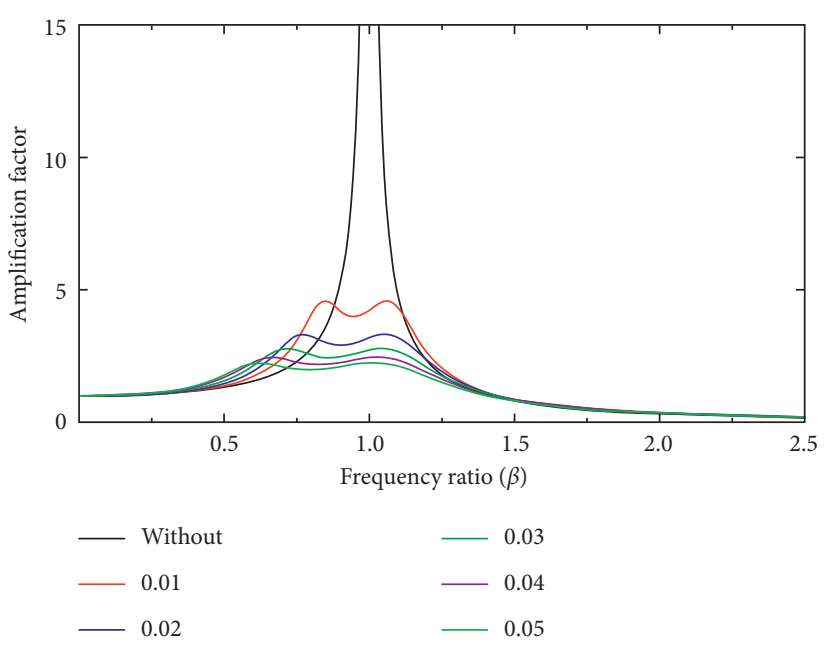

FIGURE 3: The influence of BTMD parameters on the amplification factor.

3.2. Numerical Model of the Wind Turbine. The finite element model (FEM) of the wind turbine is developed in terms of design drawings. A refined 3D FEM is not economical for the seismic vibration mitigation analysis of numerous wind turbine structures. Hence, a simple FEM is realistic. An acceptable accuracy for seismic performance could be obtained by using simplified models $[36,37]$. However, the motion of the tower is strongly associated with the motion of the blades, which reduces the natural frequency and ultimately alters the response of the tower [38]. It may significantly underestimate the structural response [39] and misunderstand the control efficiency of the BTMD without considering the blade tower coupling. Hence, two FEMs of a wind turbine, including an LFEM and a CBFEM, are modeled, as shown in Figure 5. The blades, hub, and nacelle are modeled as a lumped mass of 83.155 tons, whose gravity center shifts by $0.8 \mathrm{~m}$. The tower and lumped mass in the LFEM are modeled using the element Shell 93 and Mass 21, respectively. The connection between the tower and lump mass is modeled using the element MPC 184. The blade and nacelle in the CBFEM are modeled using the element Beam 189. The hub, which connected the blade and nacelle, is modeled as a lumped mass with infinity rigid. Generally, the wind turbine is adjusted to the parked condition (i.e., the rotor rotational speed remains zero and the electric generator does not work) under extreme events using brake rigging to reduce potential rotor motions. Therefore, the parked condition is considered in this work. The Rayleigh damping, which combines the mass and stiffness proportional damping, is used to model the recommended $1 \%$ damping [40]. The elasticity modulus of steel is $2 \times 10^{5} \mathrm{MPa}$.

The modal parameters of the first six modes, including frequency and mode shape related to the global flexure of the wind turbine tower and blade coupling, are summarized in Table 1 and Figures 6 and 7. The modal parameters of the LFEM (without blade) are comparable to that of the CBFEM (with blade), especially the first two natural frequencies. However, the blade coupling is obvious in the CBFEM. Note that blade tower coupling effects alter the third and fourth 


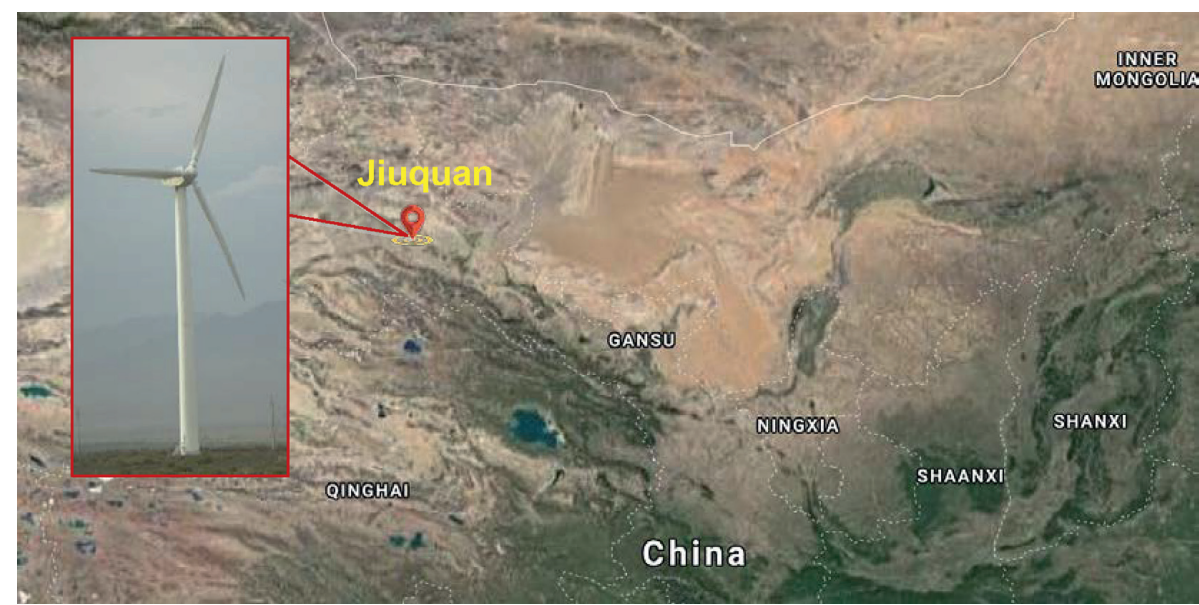

FIgURE 4: The schematic and location of wind turbine (Map Data @ 2020 Google, Imagery @ 2020 Maxar Technologies) (image by Wanrun Li).

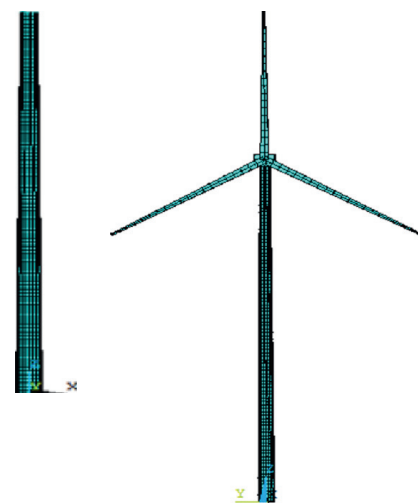

(a)

(b)

Figure 5: Numerical models of the wind turbine. (a) The LFEM. (b) The CBFEM.

TABLE 1: The modal parameters of the LFEM and CBFEM.

\begin{tabular}{|c|c|c|c|c|c|}
\hline \multirow{2}{*}{ Mode } & \multicolumn{2}{|l|}{ LFEM } & \multirow{2}{*}{ Mode } & \multicolumn{2}{|l|}{ CBFEM } \\
\hline & Mode shape & $f(\mathrm{~Hz})$ & & Mode shape & $f(\mathrm{~Hz})$ \\
\hline 1 & $1^{\text {st }}$ tower side-to-side & 0.3347 & 1 & $1^{\text {st }}$ tower side-to-side $+1^{\text {st }}$ blade edgewise & 0.3287 \\
\hline 2 & $1^{\text {st }}$ tower fore-aft & 0.3348 & 2 & $1^{\text {st }}$ tower fore-aft $+1^{\text {st }}$ blade flap-wise & 0.3314 \\
\hline 3 & $2^{\text {nd }}$ tower side-to-side & 1.7534 & 3 & $2^{\text {nd }}$ tower side-to-side $+1^{\text {st }}$ blade edgewise & 1.3973 \\
\hline 4 & $2^{\text {nd }}$ tower fore-aft & 1.7535 & 4 & $1^{\text {st }}$ blade torsion & 1.4678 \\
\hline 5 & $3^{\text {rd }}$ tower side-to-side & 4.8185 & 5 & $2^{\text {nd }}$ tower fore-aft $+1^{\text {st }}$ blade flap-wise & 1.5294 \\
\hline 6 & $3^{\text {rd }}$ tower fore-aft & 4.8203 & 6 & $2^{\text {st }}$ blade torsion & 2.7268 \\
\hline
\end{tabular}

natural frequency of the wind turbine. The frequencies decrease from 1.7534 and 1.7535 to 1.3973 and 1.4678 , respectively, whose reduction ratios are $20.31 \%$ and $16.29 \%$. Hence, the coupling effect would have significant influences on the mitigation efficiency of the BTMD.

3.3. The Finite Element Model of the BTMD. The BTMD is simplified into a bi-directional mass-spring-damper model in the FEM, as shown in Figure 8. The element Combin 14 is selected for modeling the spring-damper of the BTMD, which provides the stiffness and damping. The element Mass 21 is selected for modeling the mass block of the BTMD. Points 1, 2, 3, and 4 represent the connection points, which are located on the wind turbine. The points $5,6,7$, and 8 represent the connection points which are located on the BTMD. Point 9 represents the mass of the BTMD. The firstorder modal mass of the investigated wind turbine is 208.678 tons. Hence, the parameters of BTMD are obtained according to equations (1) to (5), as listed in Table 2. 


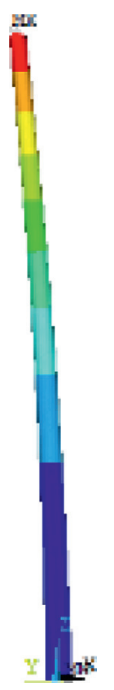

(a)

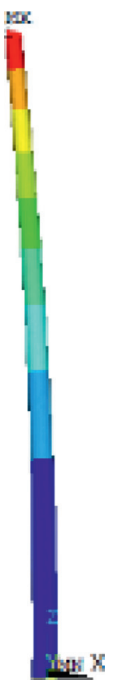

(b)

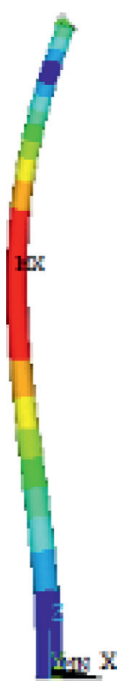

(c)

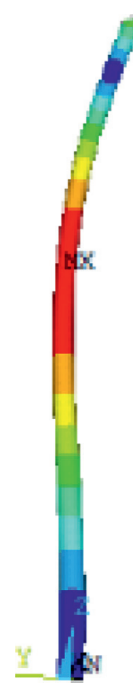

(d)

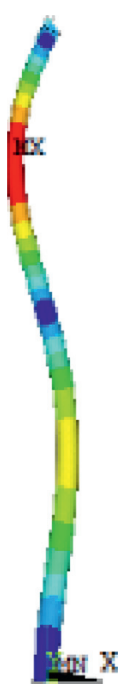

(e)

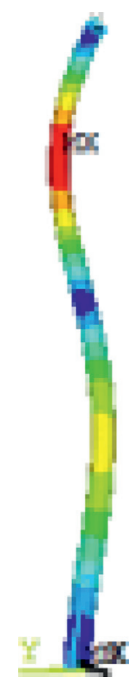

(f)

Figure 6: First six vibration mode shapes of the LFEM. (a) Mode 1. (b) Mode 2. (c) Mode 3. (d) Mode 4. (e) Mode 5. (f) Mode 6.

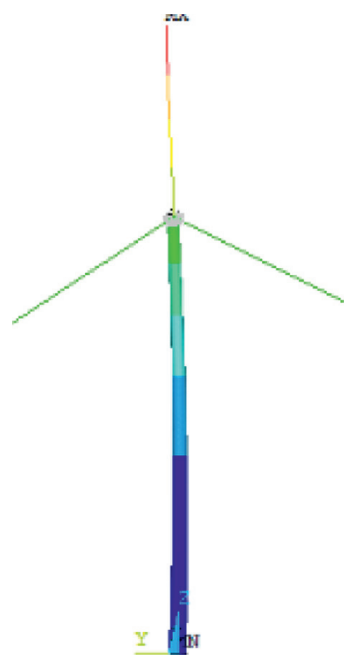

(a)

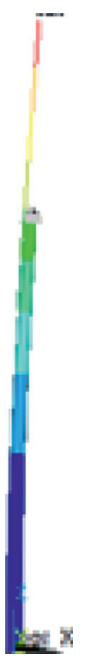

(b)

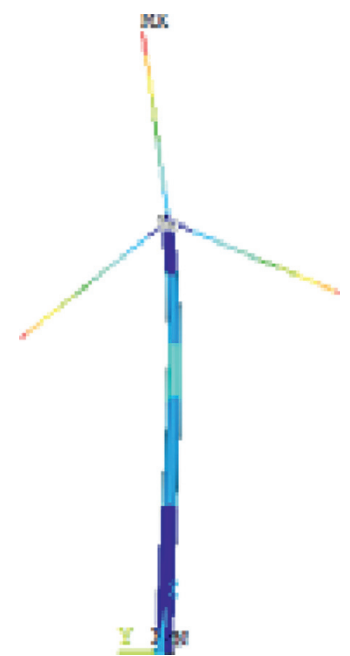

(c)

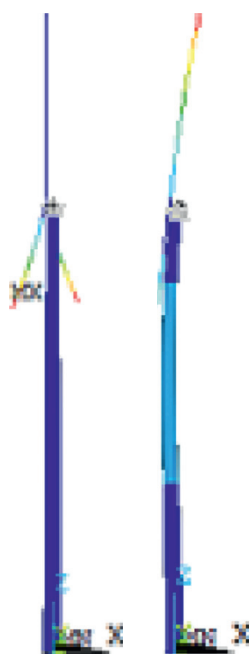

(d)

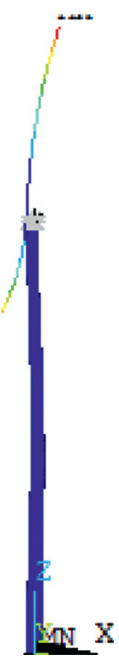

(f)

Figure 7: First six vibration mode shapes of the CBFEM. (a) Mode 1. (b) Mode 2. (c) Mode 3. (d) Mode 4. (e) Mode 5. (f) Mode 6.

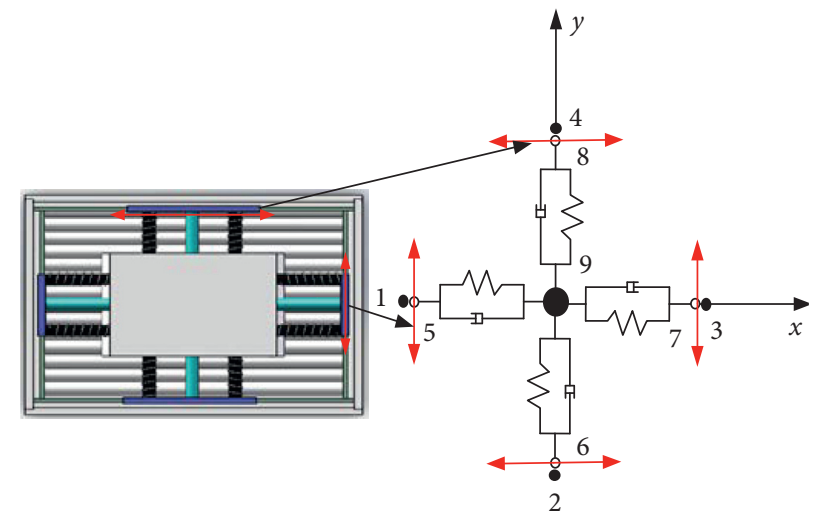

Figure 8: The mechanical model and finite element model of BTMD. 
TABle 2: Parameters of BTMD.

\begin{tabular}{ccccccc}
\hline & Mass ratio & Frequency ratio & Damping ratio (\%) & Mass $(\mathrm{kg})$ & Stiffness $(\mathrm{N} / \mathrm{m})$ & Damping $(\mathrm{N} \cdot \mathrm{s} / \mathrm{m})$ \\
\hline 1 & 0.01 & 0.9900 & 6.09 & 2086.78 & 9269.53 & 535.69 \\
2 & 0.02 & 0.9804 & 8.58 & 4173.56 & 18181.25 & 1493.93 \\
3 & 0.03 & 0.9709 & 10.45 & 6260.34 & 26744.00 & 2704.34 \\
4 & 0.04 & 0.9615 & 12.00 & 8347.12 & 34974.04 & 4100.65 \\
5 & 0.05 & 0.9523 & 13.36 & 10433.90 & 42884.94 & 5652.13 \\
\hline
\end{tabular}

\section{Structural Responses of Wind Turbines under Uni-Directional Ground Motions}

According to the Chinese code for seismic design of buildings GB 50011-2010 [41], the seismic fortification intensity of the region, in which the wind turbine prototype is located, is 8 degrees. The peak acceleration of the design earthquake is $0.2 \mathrm{~g}$. The predominant period of the site is $0.45 \mathrm{~s}$. Several studies have been conducted to investigate the simulations of the stochastic excitations for studying the dynamic responses of infrastructures, e.g., the simulation of stochastic wind field for windinduced response analysis [42-45] and artificial seismic ground motion simulations [46, 47]. To provide reliable results considering the randomness of the ground motions, two natural waves (El-Centro 1940 and Chalfant 1986) and one artificial wave, which is achieved based on the site conditions of the wind turbine prototype, are selected to investigate the seismic responses and clarify the effectiveness of the BTMD. The time histories of the selected ground motion are shown in Figure 9. The peak acceleration of the three selected ground motions is scaled to $4 \mathrm{~m} / \mathrm{s}^{2}$. Meanwhile, the spectra of these selected ground motions are shown in Figure 10, compared with the design spectrum of Chinese code. The design spectrum and the spectra of these selected ground motion records are statistically compatible. Accordingly, the displacement, acceleration, and bottom bending moment of the wind turbine tower are calculated to evaluate the vibration mitigation performance of the BTMD. The reduction ratio of structural responses is written as

$$
\eta=\frac{D_{U}-D_{C}}{D_{U}} \times 100 \%
$$

where $D_{U}$ and $D_{C}$ are the responses of the wind turbine without and with the BTMD, respectively.

4.1. Displacement of the Wind Turbine Tower. The seismic responses of the wind turbine with different mass ratios BTMD are calculated using the LFEM and CBFEM. The top displacements of the wind turbine with different mass ratios BTMD are shown in Figure 11 and Table 3. Meanwhile, the reduction ratios of peak values and standard deviations with the different mass ratios are shown in Figure 12. The top displacements and corresponding reduction ratio, produced by the CBFEM and LFEM, are similar to each other. The peak value and standard deviation of the displacement significantly decrease with the increase of the mass ratio.
However, the increases in the reduction ratio slow down with the increase of mass ratio. The maximum reduction ratios of the peak value and the standard deviation exceed $50 \%$ and $40 \%$, respectively. Hence, the BTMD can significantly mitigate the vibration of the tower, and it can be used to depress the fatigue load. Note that the reduction ratio of displacement is dependent on the characteristic of the ground motion, which is mainly influenced by the dominated frequency of the ground motion.

The peak values of the horizontal displacement along the height of the wind turbine are shown in Figure 13. The calculation of the LFEM under different ground motions is similar to that of the CBFEM. The maximum displacement occurs at the top of the wind turbine tower. The displacement of the wind turbine tower is dominated by the first mode. Hence, the reduction ratio reaches the largest when the BTMD is installed on the roof of the nacelle.

4.2. Acceleration of the Wind Turbine Tower. The accelerations of the wind turbine with different mass ratios BTMD are shown in Figure 14 and Table 4. Meanwhile, the reduction ratios of peak value and standard deviation of the top acceleration are shown in Figure 15. Compared with the displacement, the BTMD shows weak efficiency in controlling peak acceleration value, especially in the initial stage. However, the reduction ratio of the standard deviation increases with the increase of mass ratio, which can exceed $20 \%$. Hence, the BTMD can be used to depress the fatigue load.

4.3. The Bottom Bending Moment. The reduction ratios of the bottom bending moment of the wind turbine with different mass ratios BTMD are shown in Figure 16 and Table 5. The reduction ratio variation trend of the bottom bending moment is similar to that of the displacement. The BTMD can significantly mitigate the bottom bending moment, and it can be used to depress the fatigue load.

\subsection{The Fourier Spectrum of Wind Turbine Response}

4.4.1. The Fourier Spectrum of the Displacement. The Fourier spectra of the top displacement produced by the LFEM and CBFEM with different mass ratios BTMD are shown in Figure 17. The Fourier spectra of the LFEM are similar to those of the CBFEM. The structural response is mainly concentrated around the first natural frequency. One distinct peak around the fundamental frequency can be observed in the Fourier spectrum of the wind turbine without the BTMD. However, there are two peaks in the 


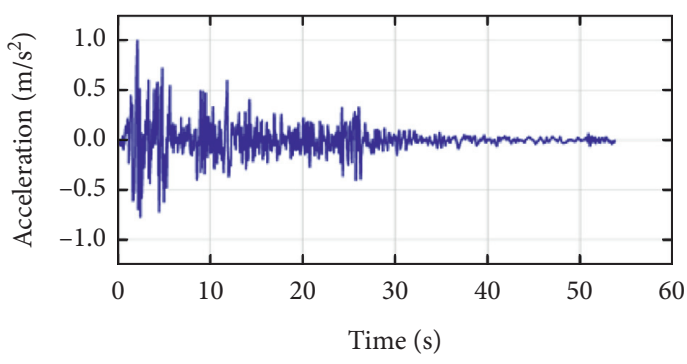

(a)

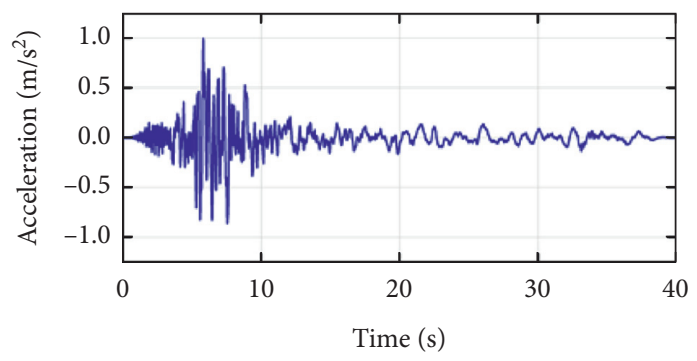

(b)

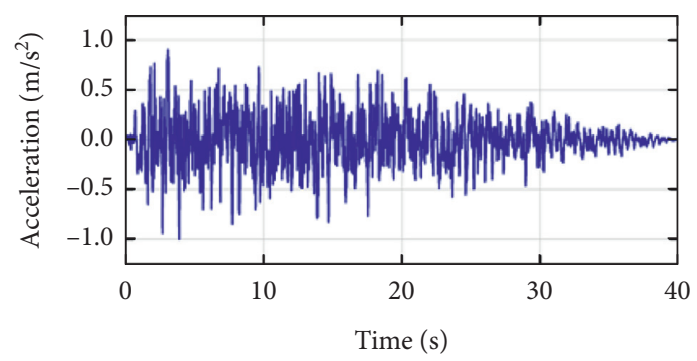

(c)

FIgure 9: The selected ground motions. (a) El-Centro. (b) Chalfant. (c) Artificial wave.

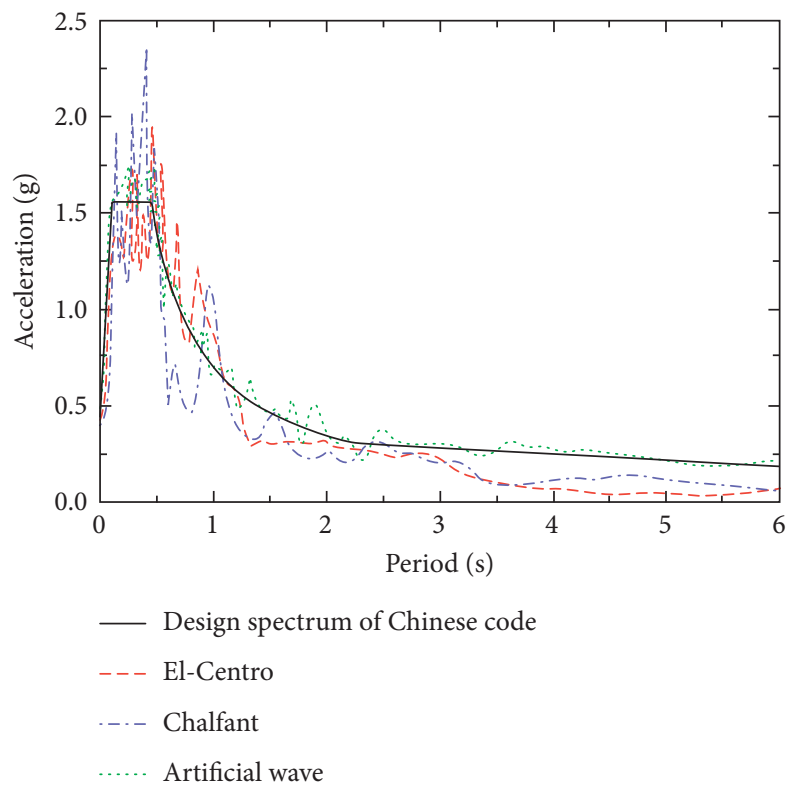

Figure 10: The spectra of the selected ground motions.

Fourier spectra of the wind turbine with the BTMD. The phenomenon is similar to the variation of the amplification factor, as shown in Figure 3. Note that the amplitude of the peak frequency decreases with the increase of mass ratio due to the excellent mitigation performance of the BTMD. The vibration energy of the wind turbine can be dissipated effectively by the BTMD.

4.4.2. The Fourier Spectrum of the Acceleration. The Fourier spectra of the LFEM and CBFEM with different mass ratios of BTMD subjected to different ground motions are shown in
Figure 18. The Fourier spectra of the LFEM are similar to those of the CBFEM. Compared with the Fourier spectra of the displacement, the frequency peaks appear around the first two natural frequencies. The amplitude around the first natural frequency decreases significantly with the increase of mass ratio, whereas the amplitude variation around the second natural frequency is small. It may be illustrated by the reason that the BTMD is designed according to the foundational frequency of the wind turbine. Hence, the BTMD can significantly mitigate the amplitude of the controlled frequency. However, it shows weak efficiency on the amplitude mitigation of other frequencies. 

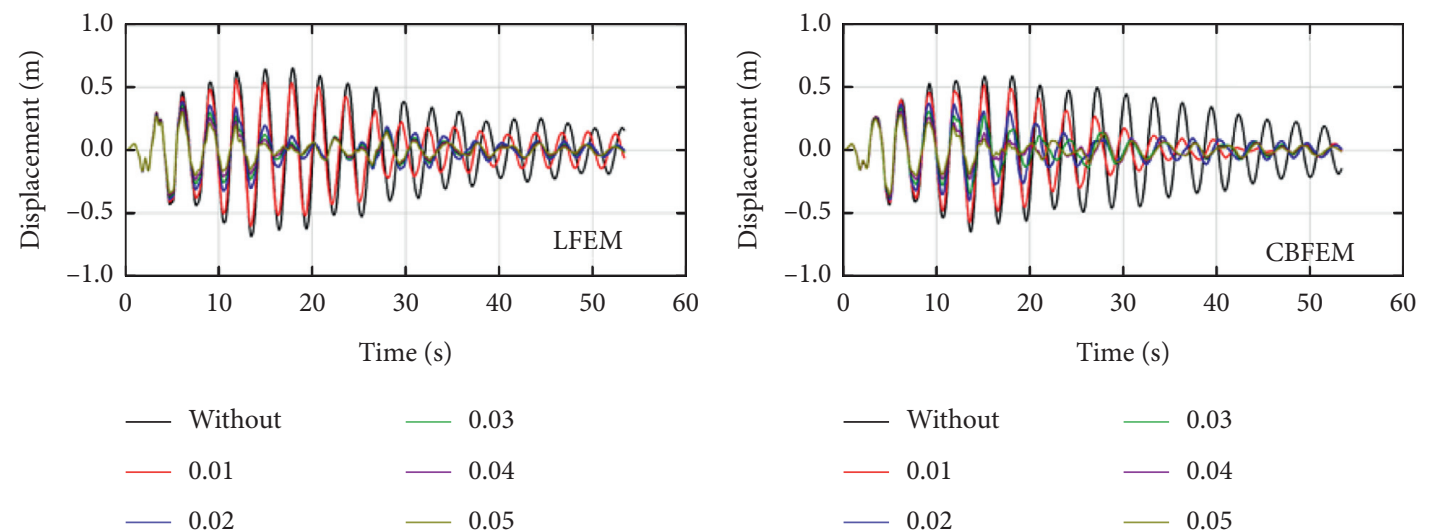

(a)

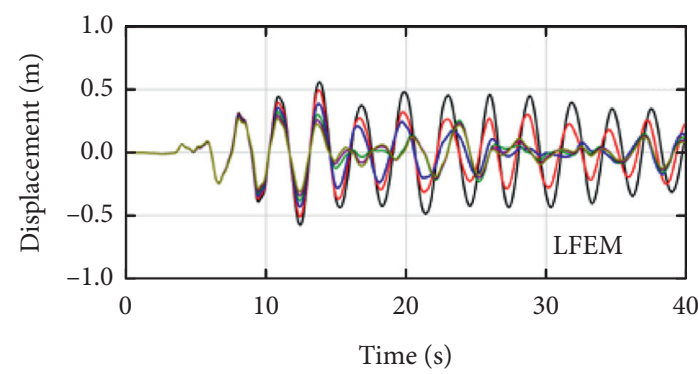

(b)
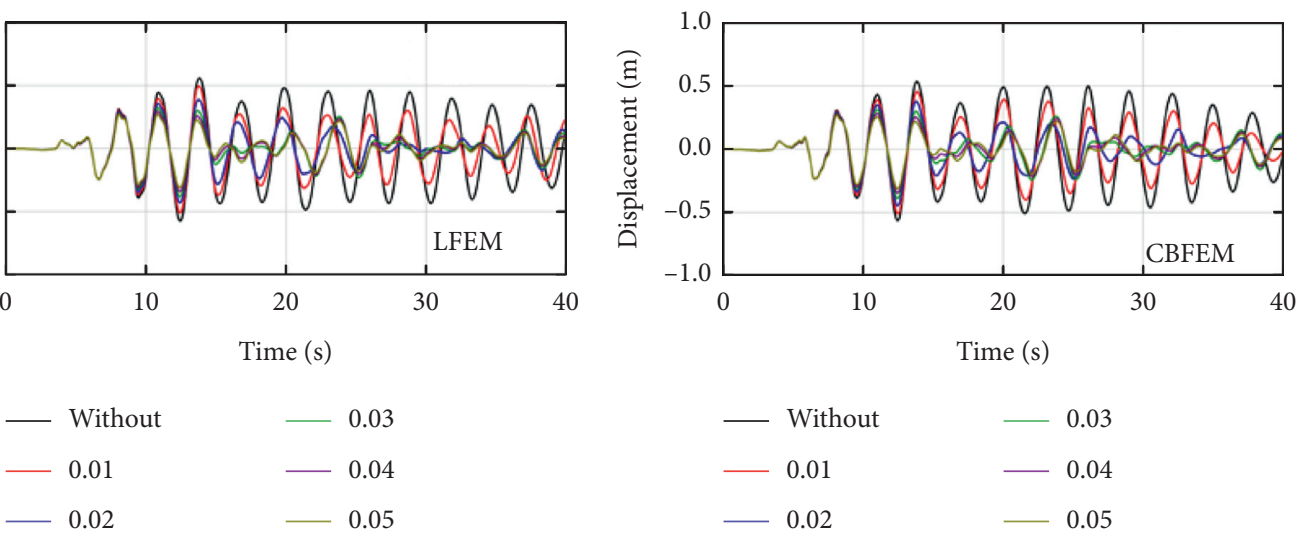

(c)

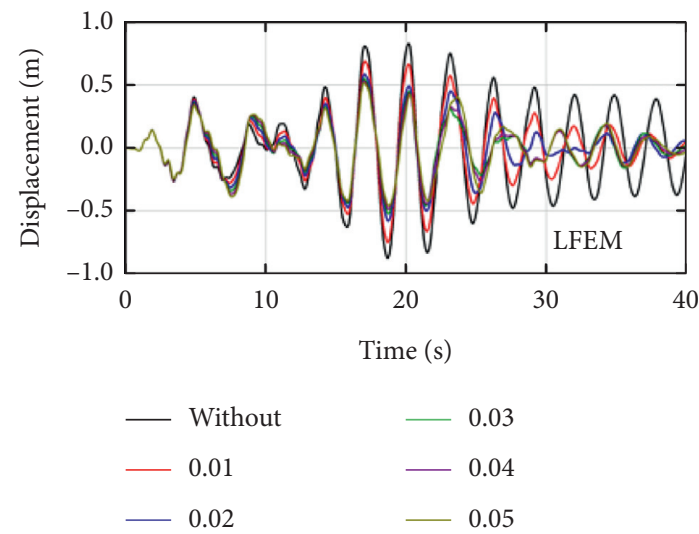

(e)

(d)

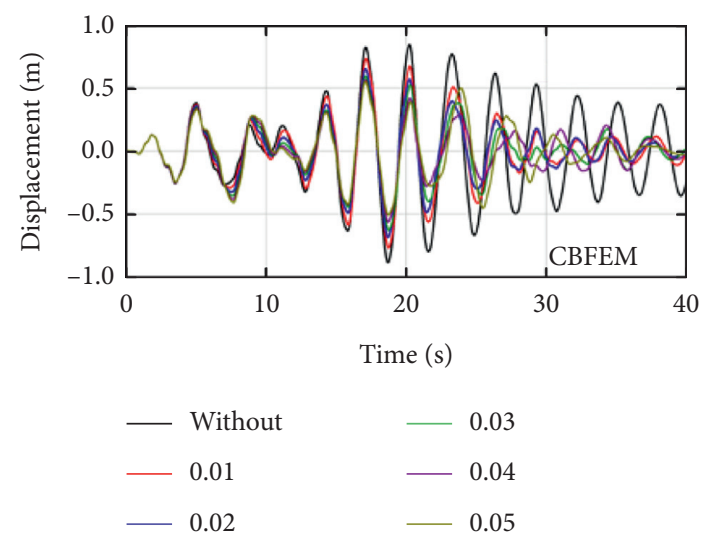

(f)

FIgure 11: The displacement of wind turbine. (a) LFEM under the El-Centro. (b) CBFEM under the El-Centro. (c) LFEM under the Chalfant. (d) CBFEM under the Chalfant. (e) LFEM under artificial wave. (f) CBFEM under artificial wave.

\section{Seismic Response of the Wind Turbine under Bi-Directional Ground Motion}

The wind turbine would suffer bi-directional vibration (fore-aft and side-side) due to bi-directional earthquakes. It is meaningful to investigate the effectiveness of the BTMD in the vibration control of wind turbines under bidirectional earthquakes. According to the Chinese code for the seismic design of buildings, the amplitude ratios of two direction ground motions are modulated to $1.0: 0.85$. The seismic responses of the wind turbine under bi-directional ground motion are calculated using the LFEM and CBFEM.

5.1. The Structural Responses Reduction. The reduction ratios of the displacement, acceleration, and bottom bending moment in the two directions calculated using the LFEM and CBFEM are shown in Figures 19-21, respectively. The reduction ratios of the peak value 
TABLE 3: The displacement of the wind turbine with different mass ratios BTMD.

\begin{tabular}{lcccccc}
\hline \multirow{2}{*}{ Mass ratio } & \multicolumn{2}{c}{ El-Centro } & \multicolumn{2}{c}{ Chalfant } & \multicolumn{2}{c}{ Artificial wave } \\
& LFEM & CBFEM & LFEM & CBFEM & 0.53 & 0.83 \\
Without & 0.65 & 0.63 & 0.56 & 0.45 & 0.69 \\
0.01 & 0.56 & 0.52 & 0.49 & 0.37 & 0.59 \\
0.02 & 0.38 & 0.37 & 0.38 & 0.31 & 0.55 \\
0.03 & 0.35 & 0.33 & 0.31 & 0.28 & 0.53 \\
0.04 & 0.31 & 0.30 & 0.29 & 0.27 & 0.54 \\
0.05 & 0.30 & 0.28 & 0.27 & & 0.52 \\
\hline
\end{tabular}
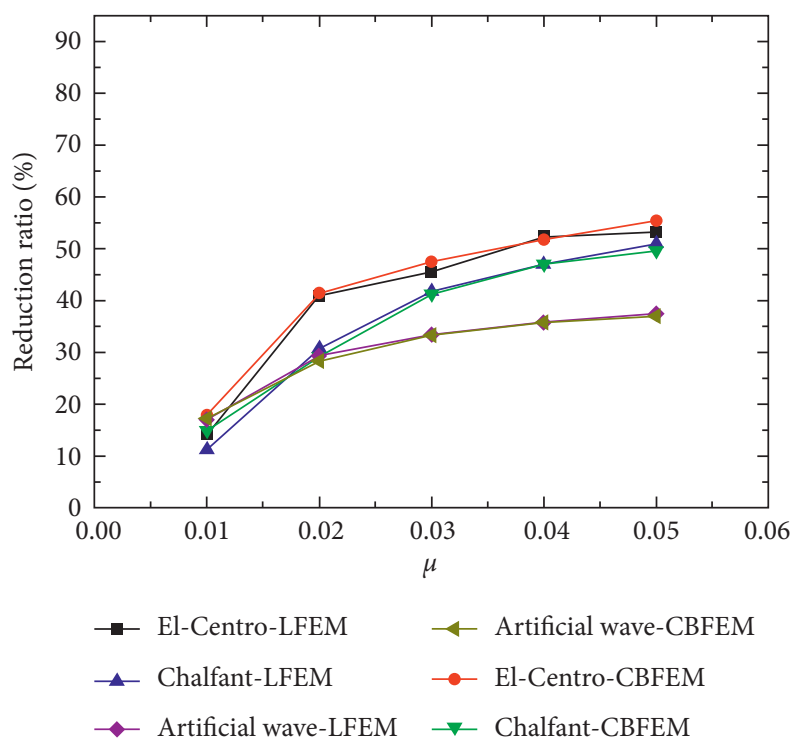

(a)
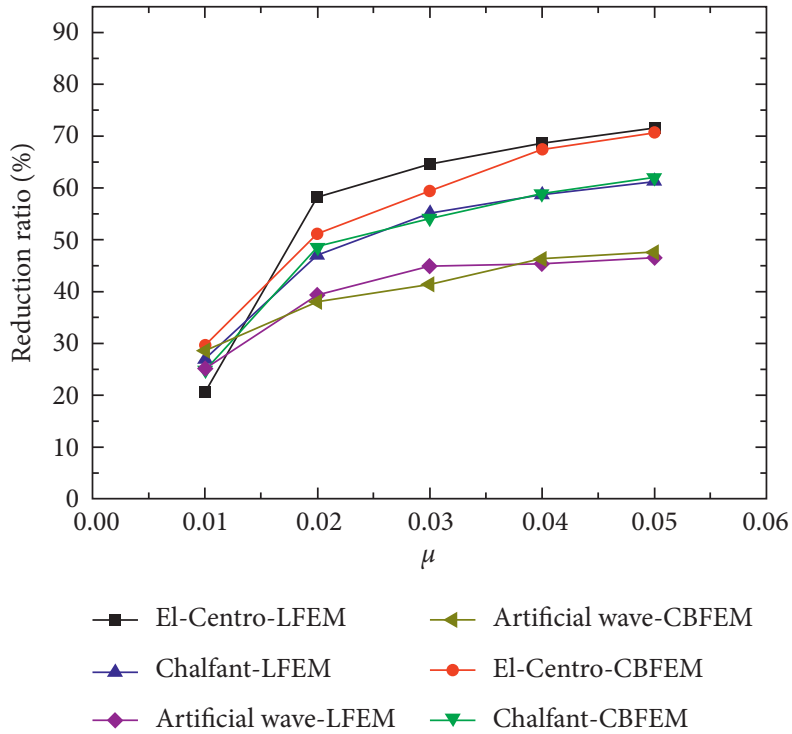

(b)

Figure 12: The reduction ratio of displacements. (a) Peak displacement. (b) The standard deviation of displacement.

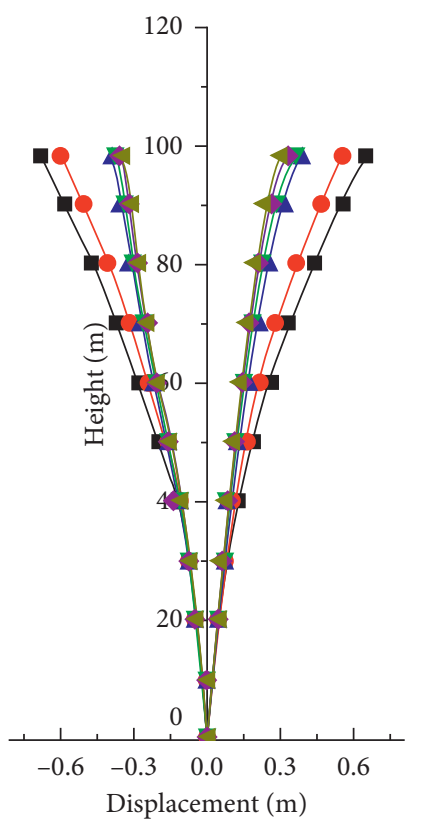

LFEM

$\rightarrow-$ Without

- 0.01

$\leftarrow 0.02$

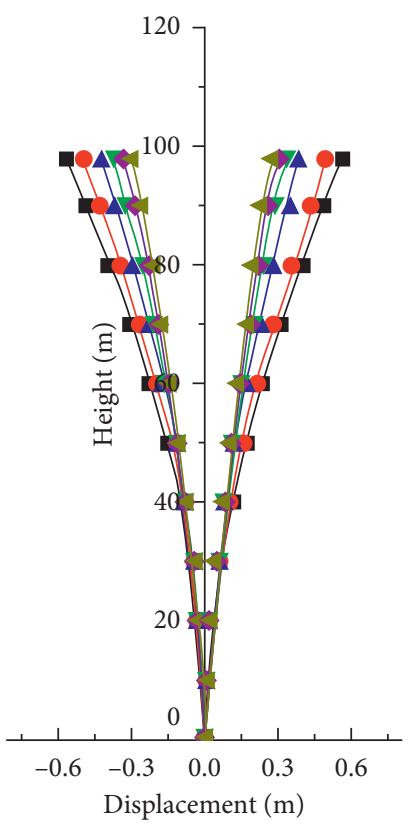

LFEM

- Without

$\longrightarrow 0.01$

$\rightarrow 0.02$

$\rightarrow \quad 0.03$

$\multimap 0.04$

$+0.05$

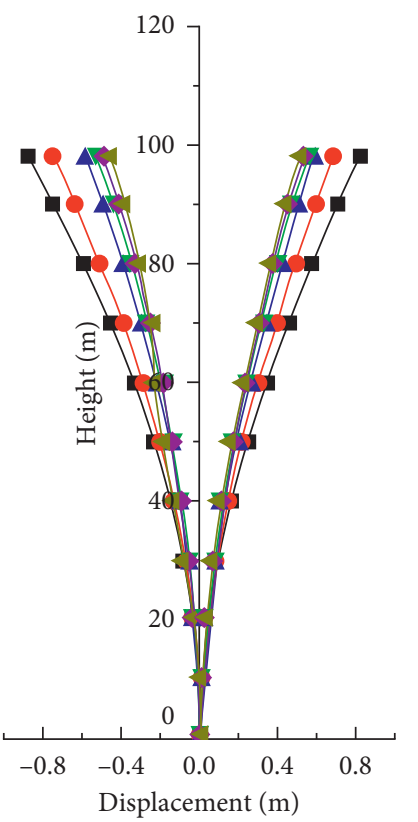

LFEM

(b) $\rightarrow$ Without

- 0.01

$\longrightarrow 0.02$ (c)

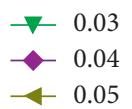

(a)
Figure 13: Continued.

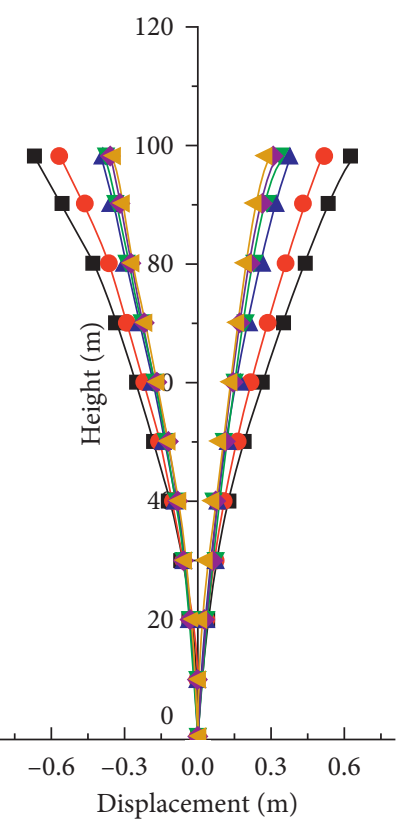

CBFEM

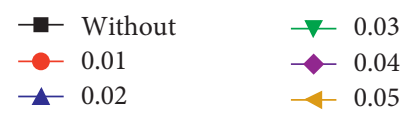

(d) 

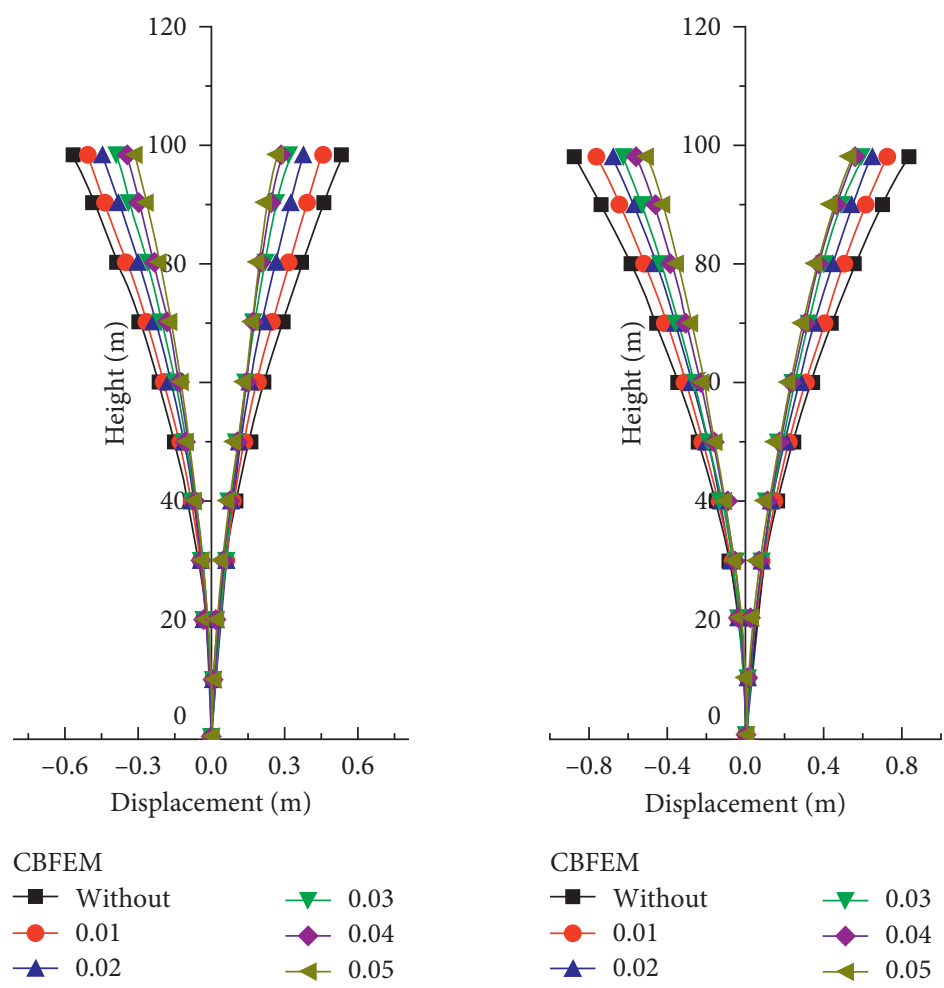

(e)

(f)

FIGURE 13: The peak displacement of wind turbine along the height. (a) LFEM under the El-Centro. (b) LFEM under the Chalfant. (c) LFEM under artificial wave. (d) CBFEM under the El-Centro. (e) CBFEM under the Chalfant. (f) CBFEM under artificial wave.
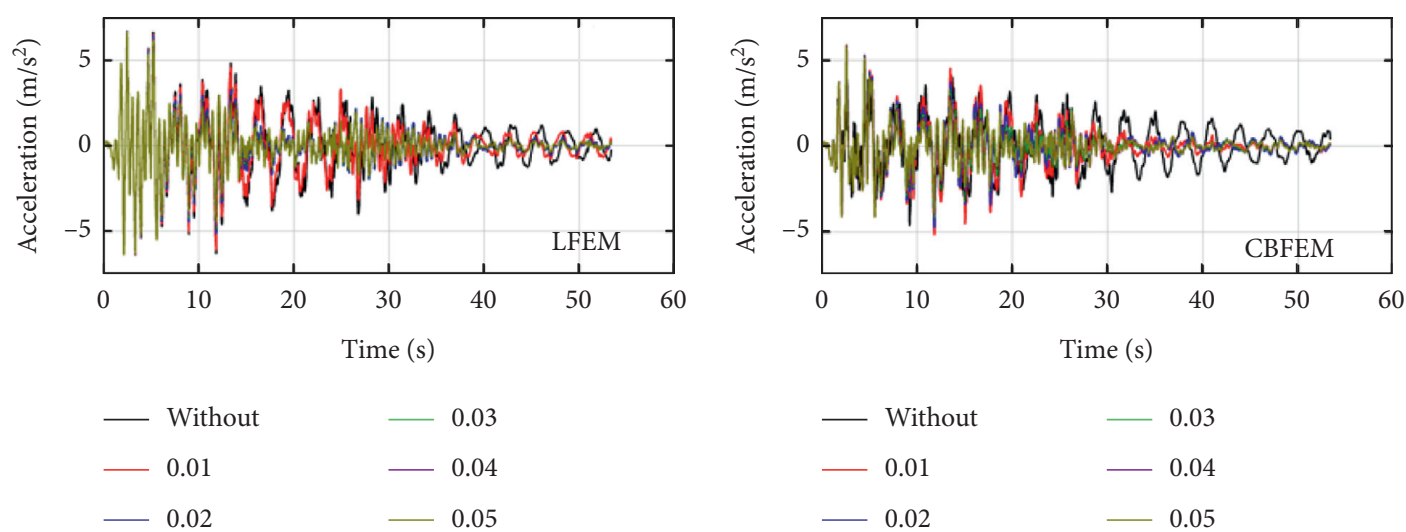

(a)

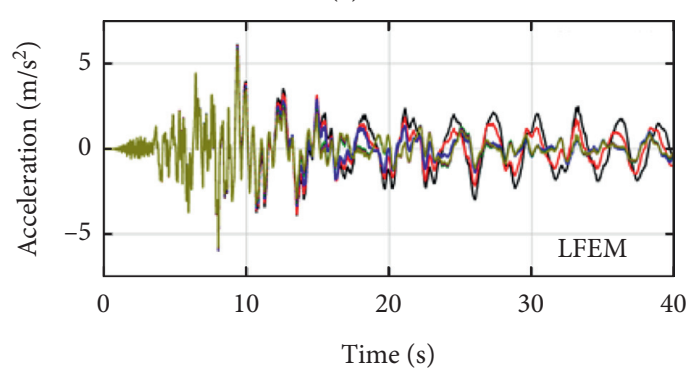

(b)
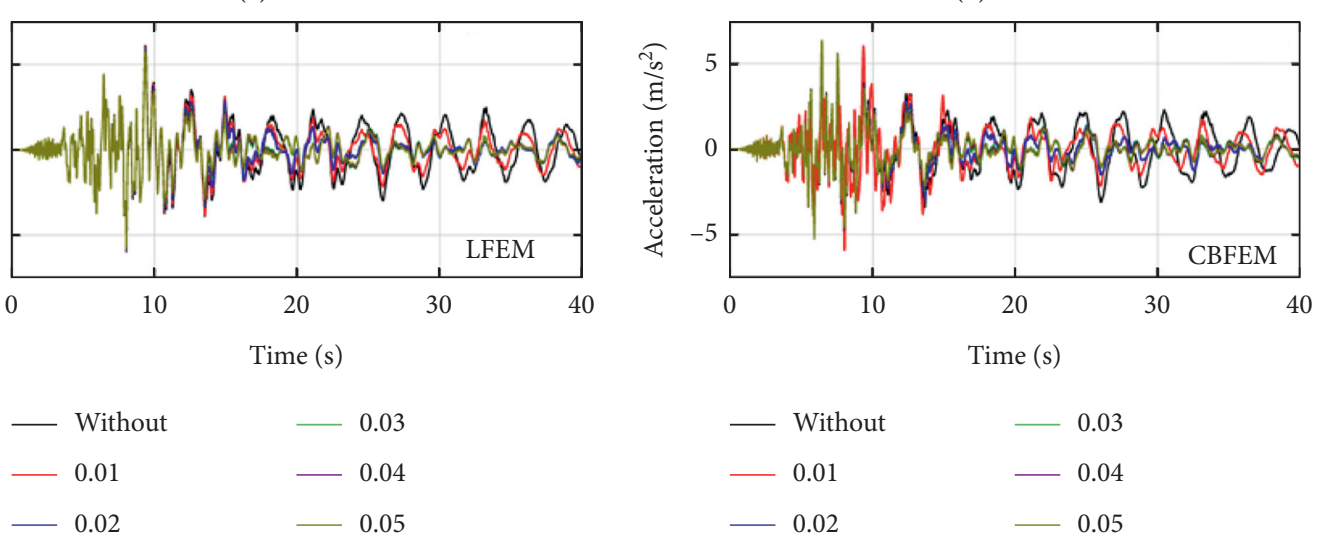

(c)

(d)

Figure 14: Continued. 


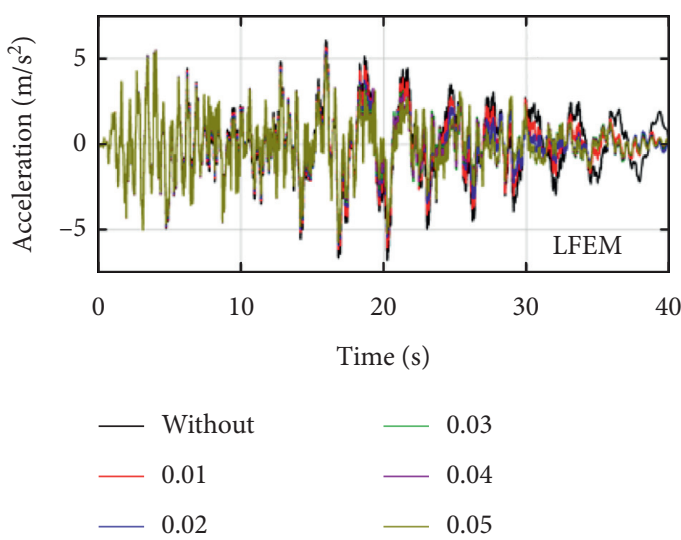

(e)

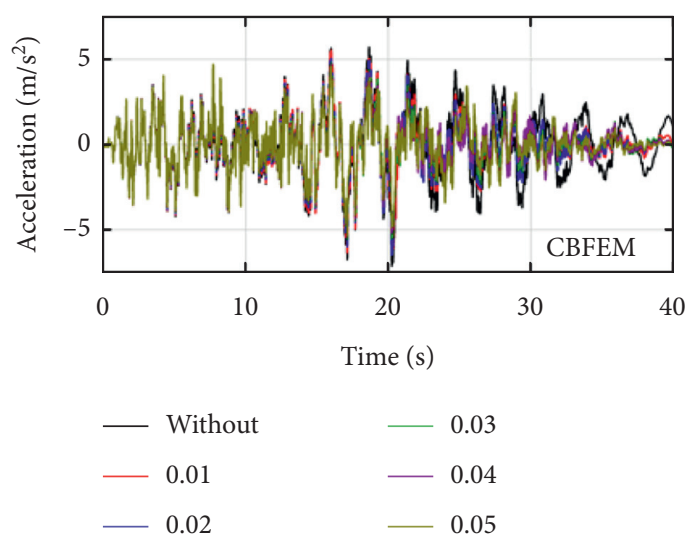

(f)

FIGURE 14: The acceleration of the wind turbine with different mass ratios BTMD. (a) LFEM under El-Centro. (b) CBFEM under the ElCentro. (c) LFEM under the Chalfant. (d) CBFEM under the Chalfant. (e) LFEM under artificial wave. (f) CBFEM under artificial wave.

TABLE 4: The peak acceleration of the wind turbine with different mass ratios BTMD.

\begin{tabular}{lcccccc}
\hline \multirow{2}{*}{ Mass ratio } & \multicolumn{2}{c}{ El-Centro } & \multicolumn{2}{c}{ Chalfant } & \multicolumn{2}{c}{ Artificial wave } \\
& LFEM & CBFEM & LFEM & CBFEM & LFEM & CBFEM \\
\hline Without & 6.68 & 5.87 & 6.12 & 5.73 & 5.08 \\
0.01 & 6.67 & 5.85 & 6.04 & 5.61 & 5.66 & 5.52 \\
0.02 & 6.66 & 5.83 & 5.97 & 5.46 & 5.44 & 5.43 \\
0.03 & 6.64 & 5.81 & 5.90 & 5.41 & 5.43 \\
0.04 & 6.63 & 5.80 & 5.83 & 5.37 & 5.13 \\
0.05 & 6.62 & 5.78 & 5.76 & & 5.42 \\
\hline
\end{tabular}

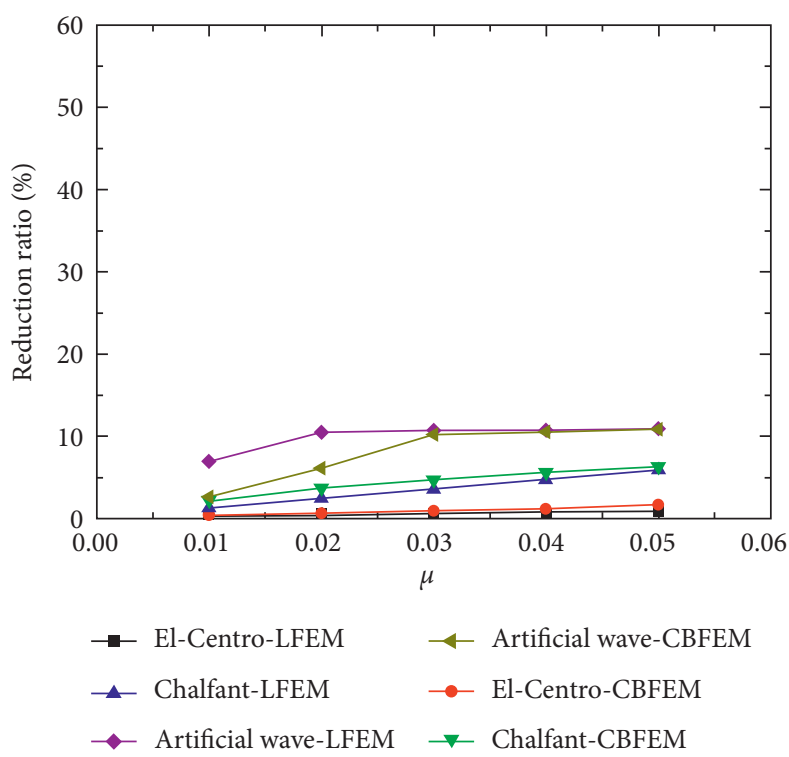

(a)

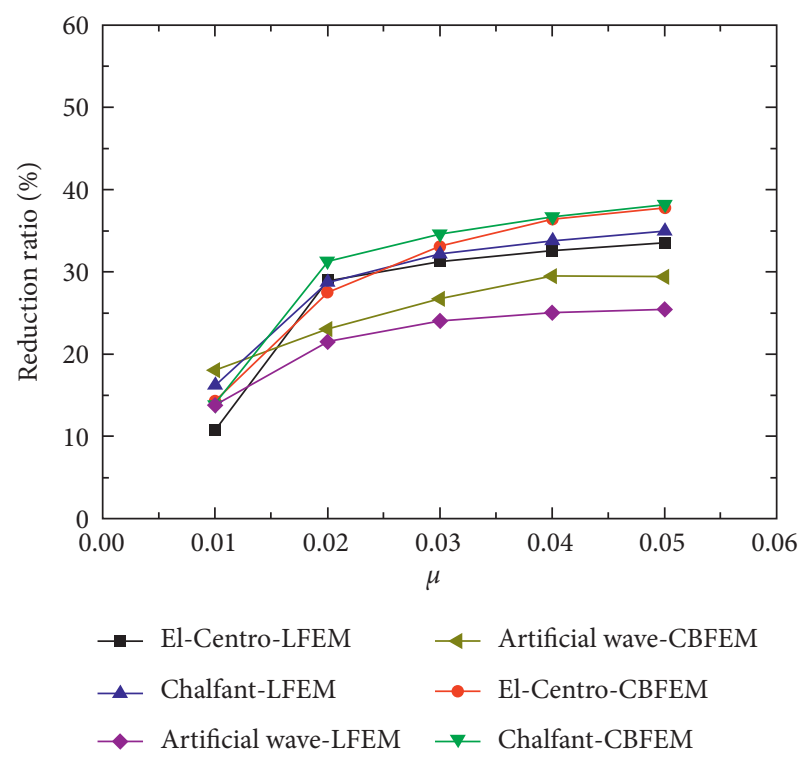

(b)

Figure 15: The reduction ratio of (a) the peak acceleration and (b) the peak acceleration standard deviation.

and standard deviation in two directions are similar to each other, which increase with the augment of the mass ratio. The reduction ratio of the peak displacement exceeds $20 \%$. The BTMD can efficiently reduce the bi-directional peak displacement. However, the reduction ratios of peak acceleration are small. It is challenging to reduce the peak acceleration using the BTMD. Meanwhile, the standard deviation reduction ratios of the displacement, acceleration, and bottom bending moment can exceed 40\%, 20\%, and 30\%, respectively. Hence, the proposed BTMD can efficiently depress the fatigue load of wind turbines. Note that the reduction ratio 

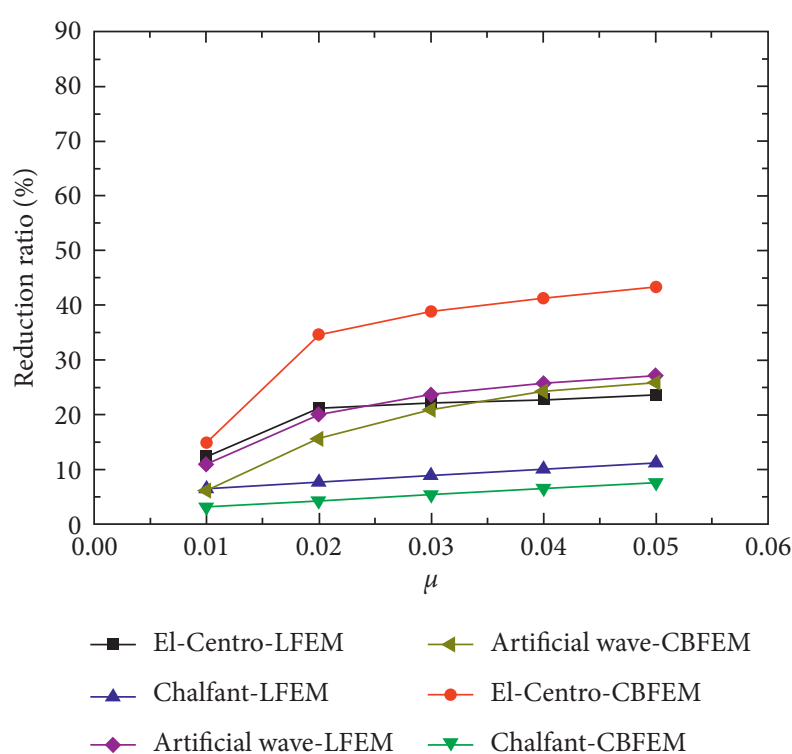

(a)

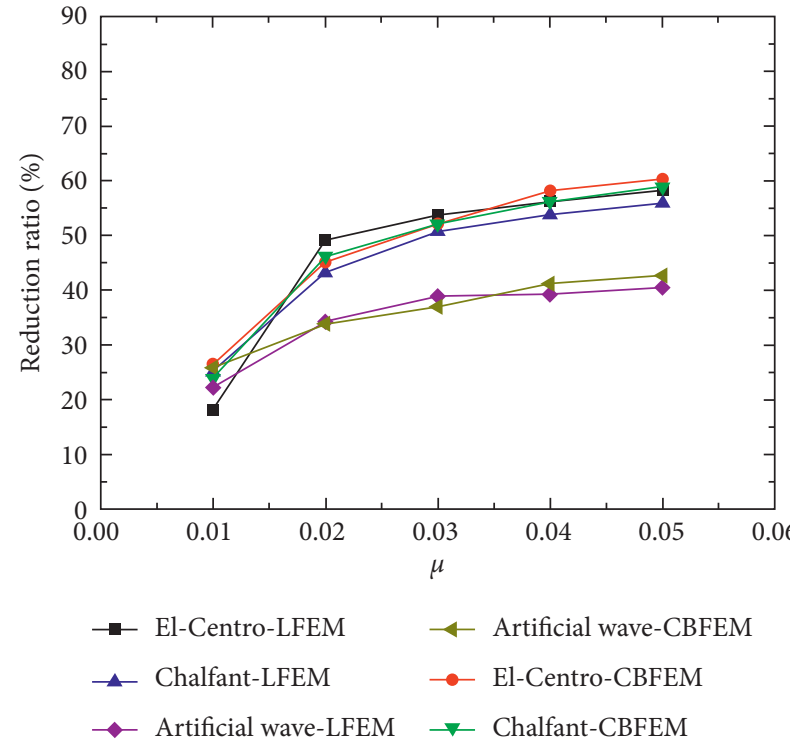

(b)

FIGURE 16: The reduction ratio of (a) the peak bending moment and (b) the standard deviation of bending moment.

TABLE 5: The bottom bending moment of the wind turbine with different mass ratios of BTMD.

\begin{tabular}{|c|c|c|c|c|c|c|}
\hline \multirow{2}{*}{ Mass ratio } & \multicolumn{2}{|c|}{ El-Centro } & \multicolumn{2}{|c|}{ Chalfant } & \multicolumn{2}{|c|}{ Artificial wave } \\
\hline & LFEM & CBFEM & LFEM & CBFEM & LFEM & CBFEM \\
\hline Without & 50989.6 & 48402.90 & 39391.70 & 36431.90 & 64822.80 & 62616.90 \\
\hline 0.01 & 44702.4 & 41204.40 & 36846.60 & 35289.10 & 57728.02 & 58764.70 \\
\hline 0.02 & 40158.8 & 31663.20 & 36374.10 & 34873.00 & 51209.89 & 52848.00 \\
\hline 0.03 & 39741.6 & 29572.00 & 35905.60 & 34463.80 & 48794.62 & 49514.90 \\
\hline 0.04 & 39347.7 & 28437.10 & 35443.00 & 34059.20 & 47383.48 & 47441.00 \\
\hline 0.05 & 38957.2 & 27424.70 & 34987.60 & 33661.30 & 46466.11 & 46423.00 \\
\hline
\end{tabular}

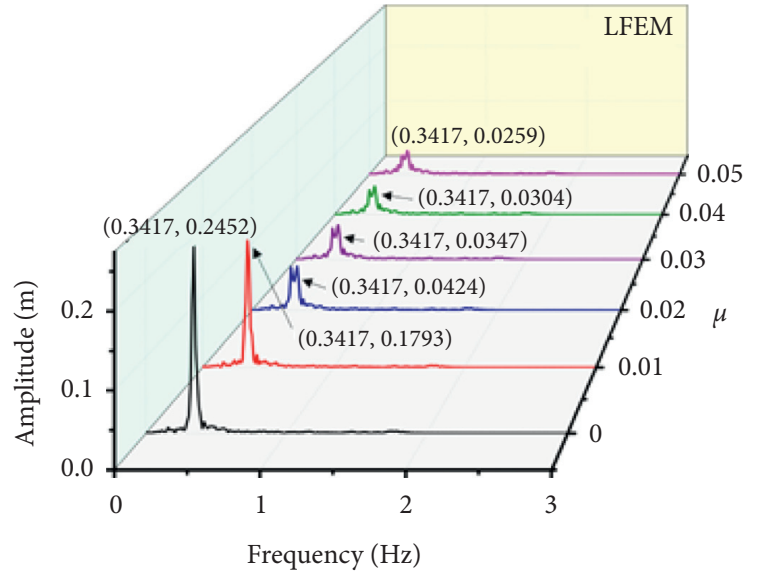

(a)

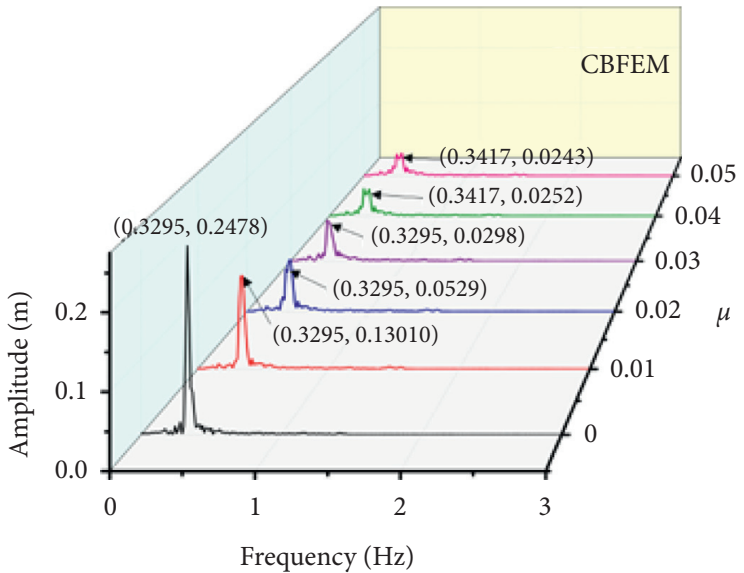

(b)

Figure 17: Continued. 


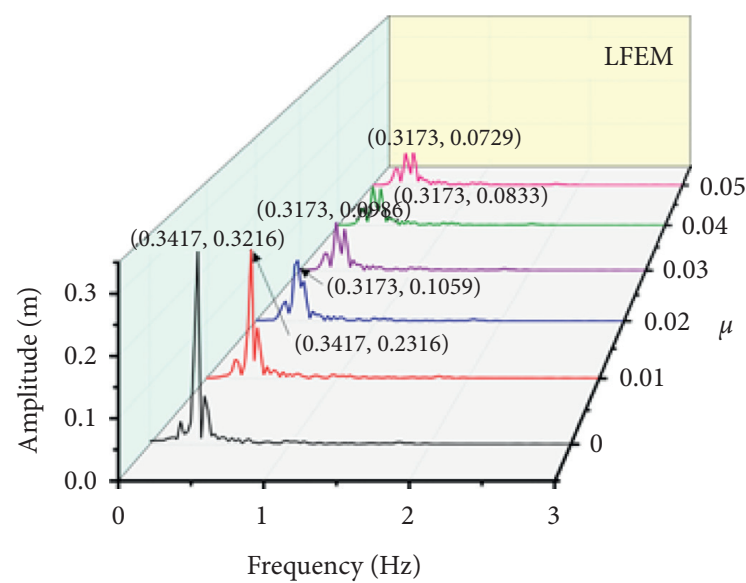

(c)

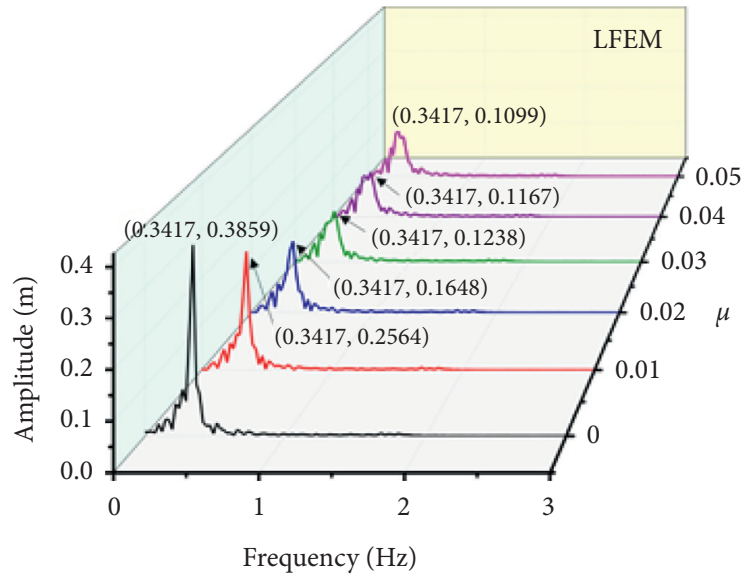

(e)

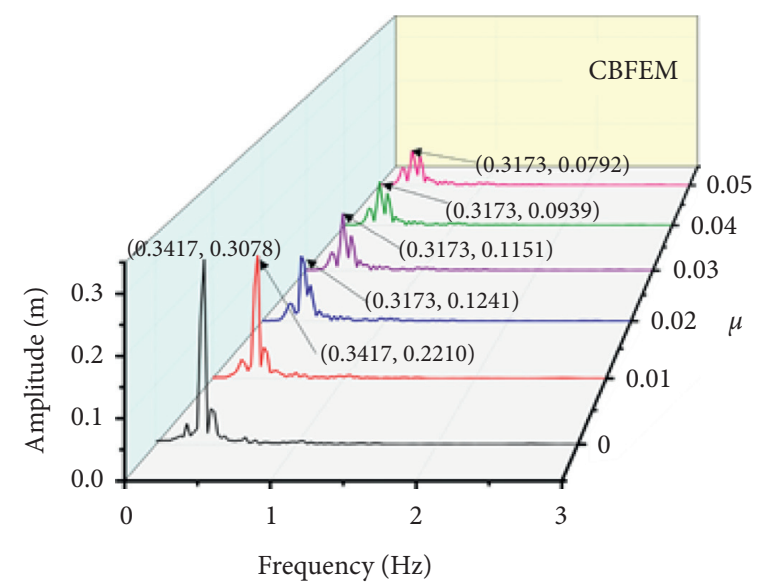

(d)

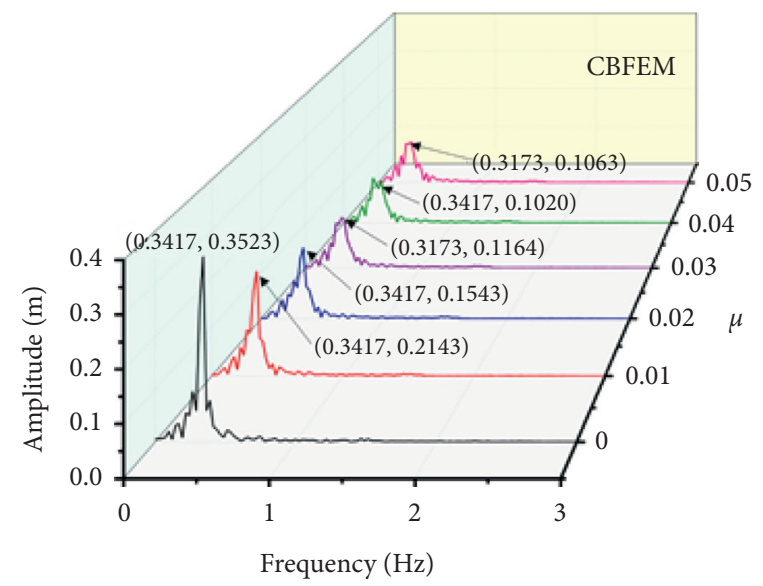

(f)

FIGURE 17: The Fourier spectra of the top displacement. (a) LFEM under the El-Centro. (b) CBFEM under the El-Centro. (c) LFEM under the Chalfant. (d) CBFEM under the Chalfant. (e) LFEM under artificial wave. (f) CBFEM under artificial wave.

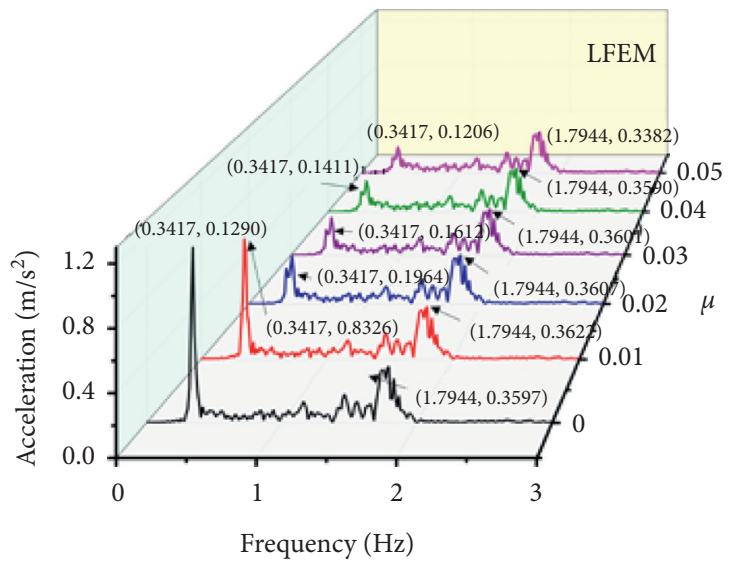

(a)

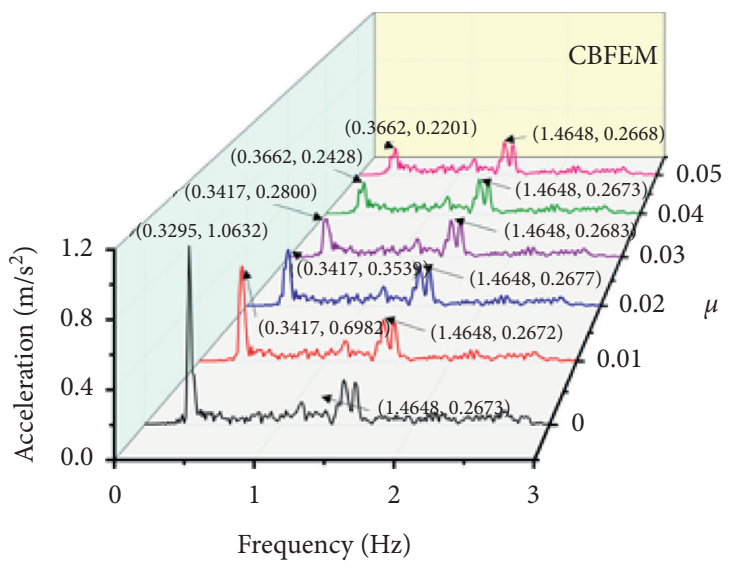

(b)

FIGURE 18: Continued. 


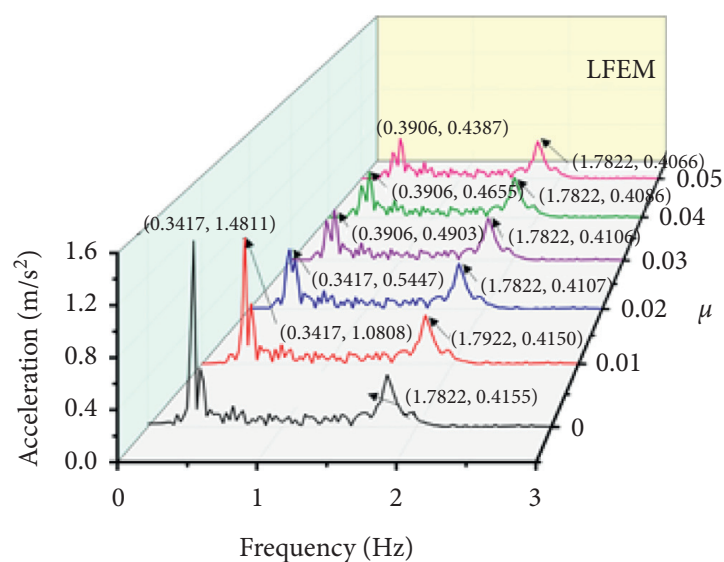

(c)

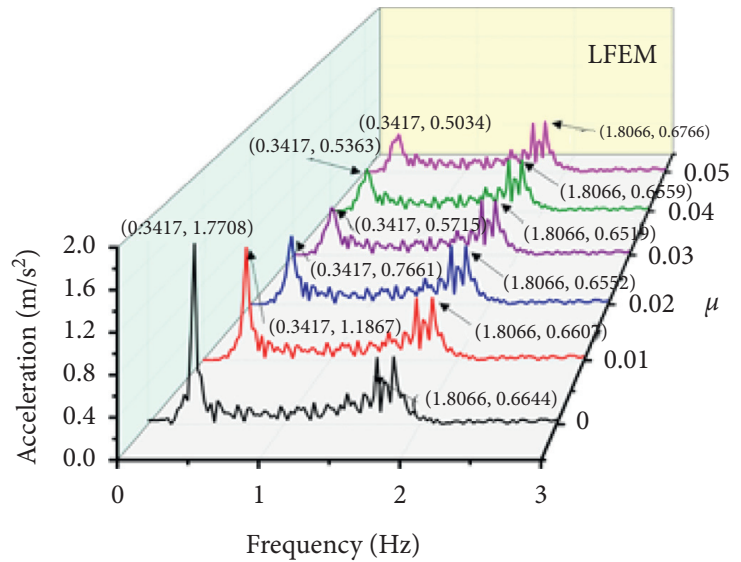

(e)

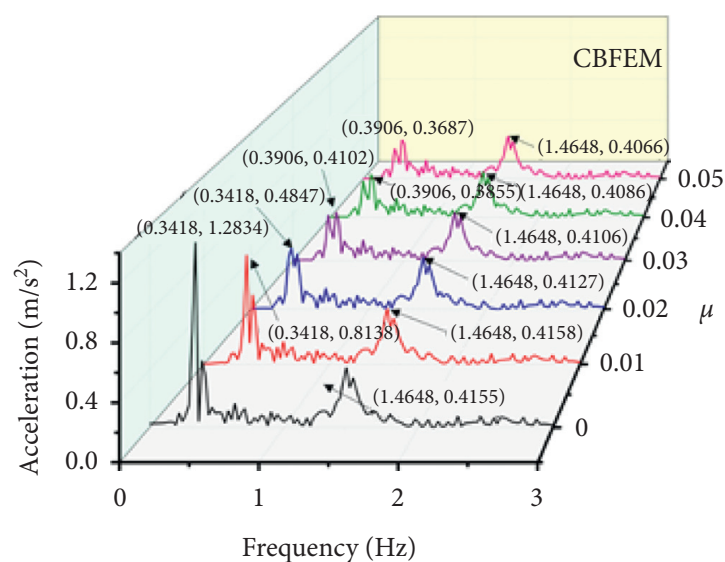

(d)

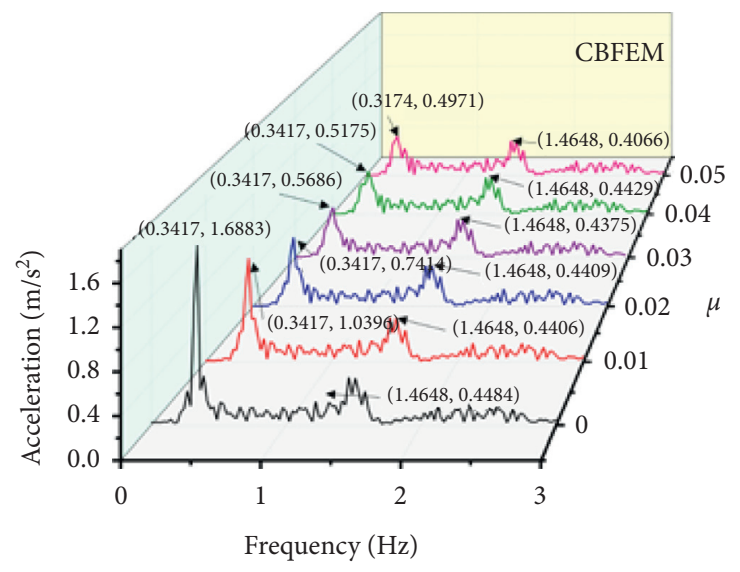

(f)

FIgURE 18: The Fourier spectrum of the top acceleration. (a) LFEM under the El-Centro. (b) CBFEM under the El-Centro. (c) LFEM under the Chalfant. (d) CBFEM under the Chalfant. (e) LFEM under artificial wave. (f) CBFEM under artificial wave.

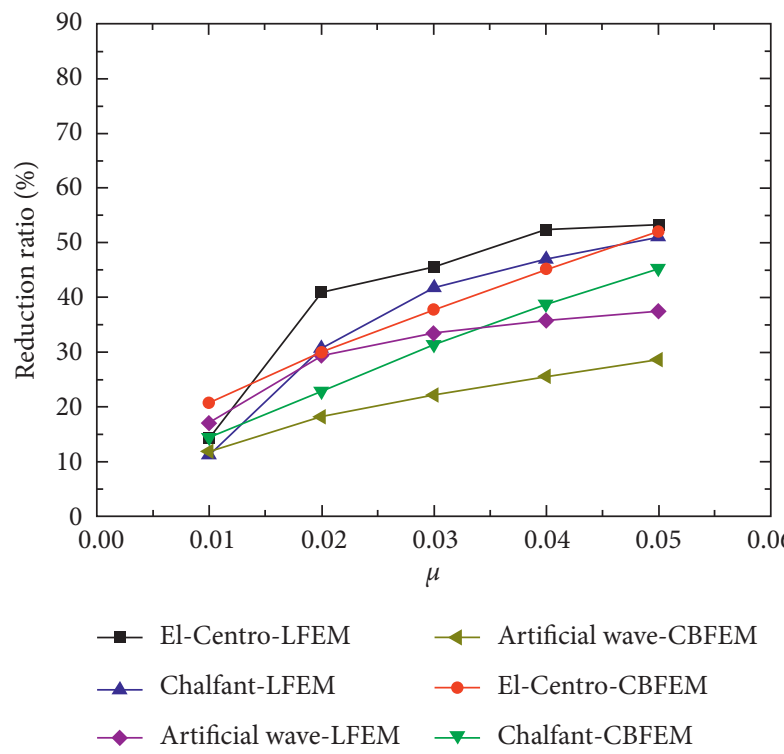

(a)

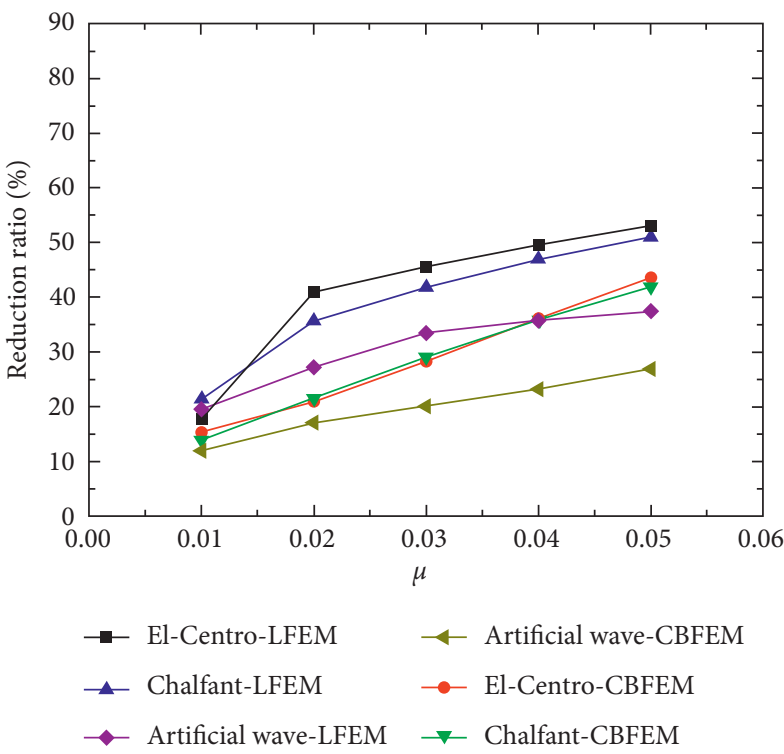

(b)

Figure 19: Continued. 


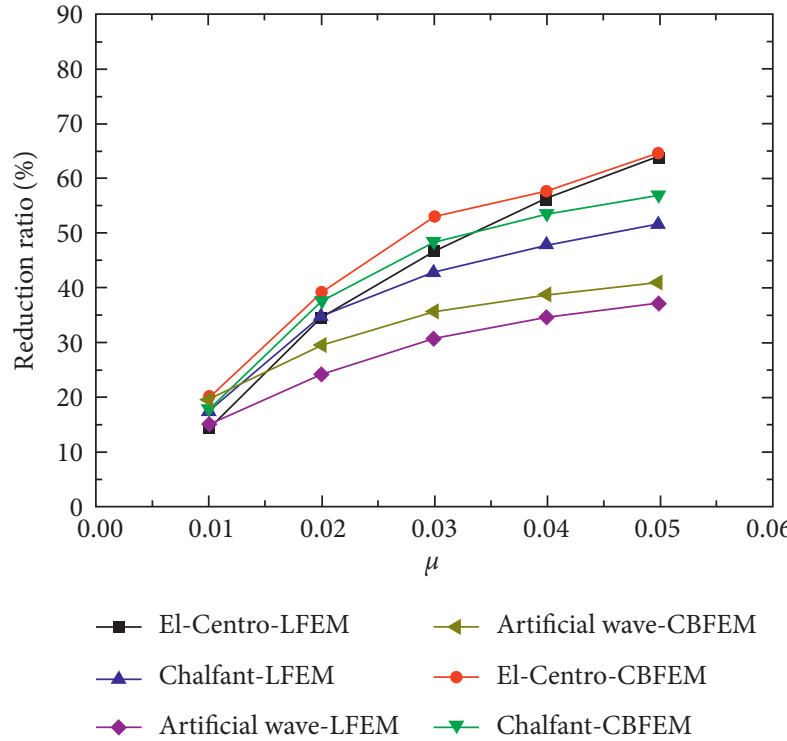

(c)

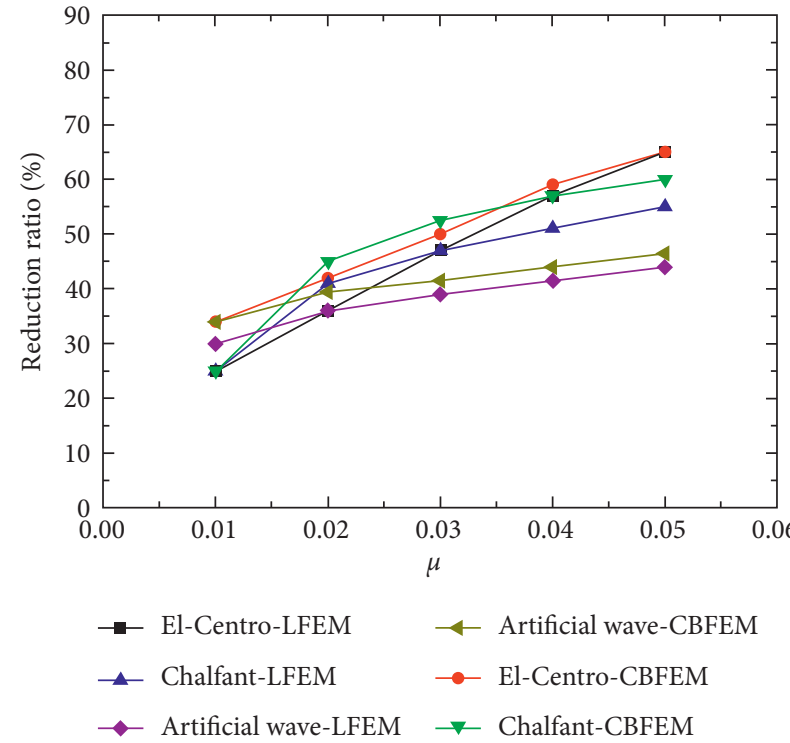

(d)

Figure 19: The reduction ratio of displacement produced by bi-directional ground motion. (a) Displacement in fore-aft direction. (b) Displacement in side-side direction. (c) Displacement standard deviation in fore-aft direction. (d) Displacement standard deviation in side-side direction.

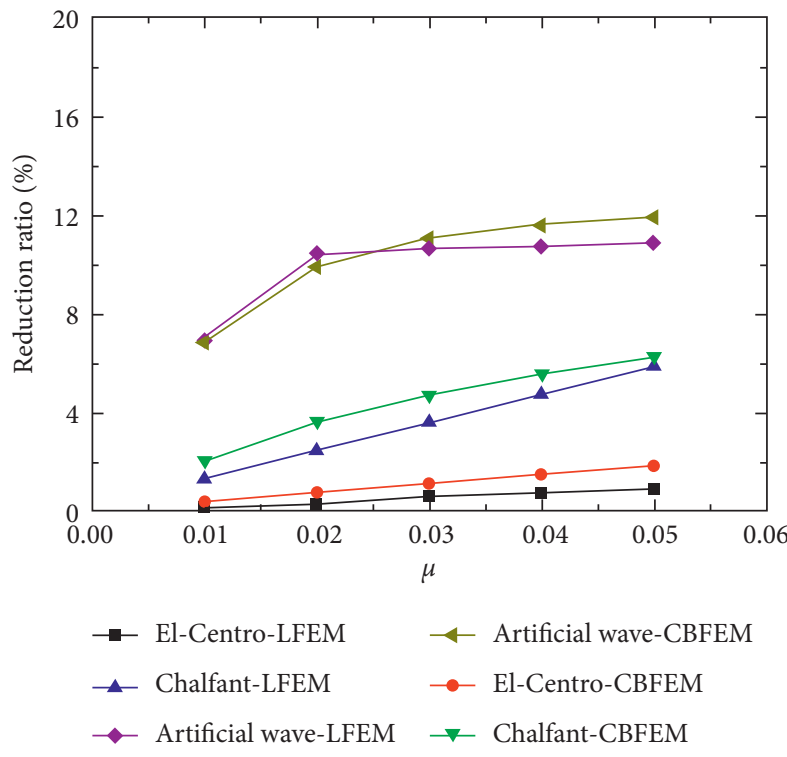

(a)

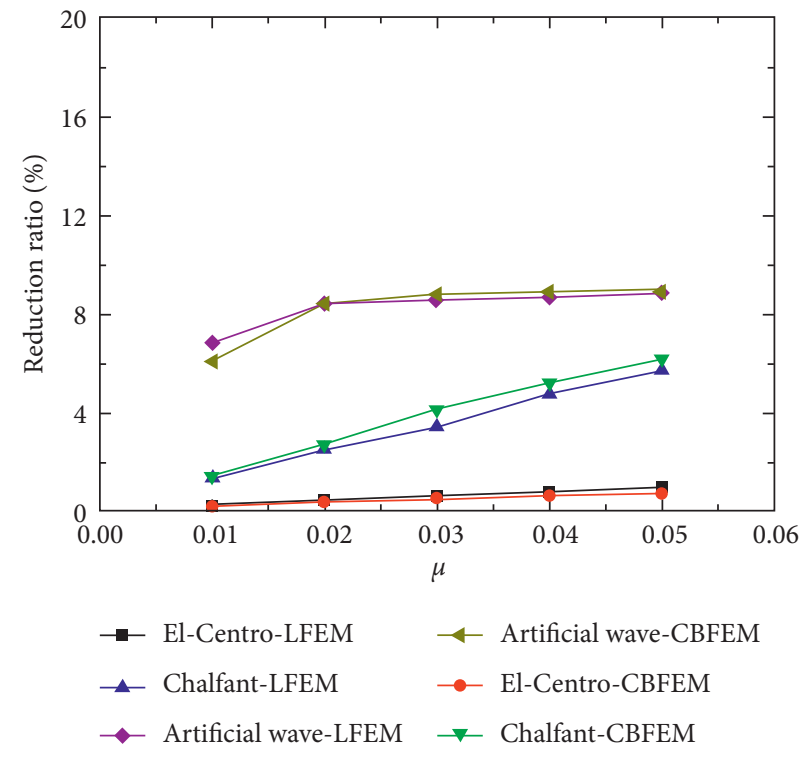

(b)

Figure 20: Continued. 


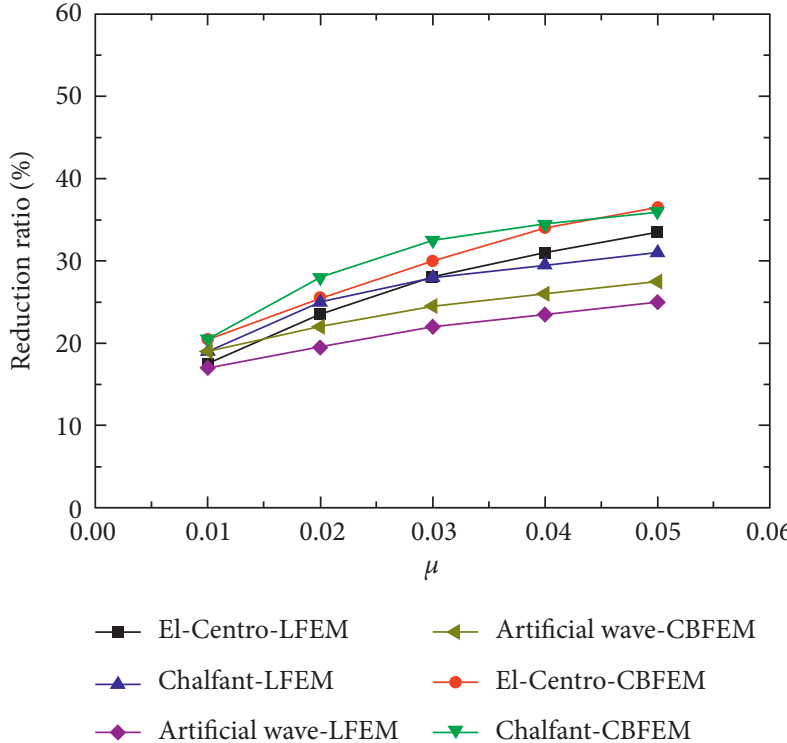

(c)

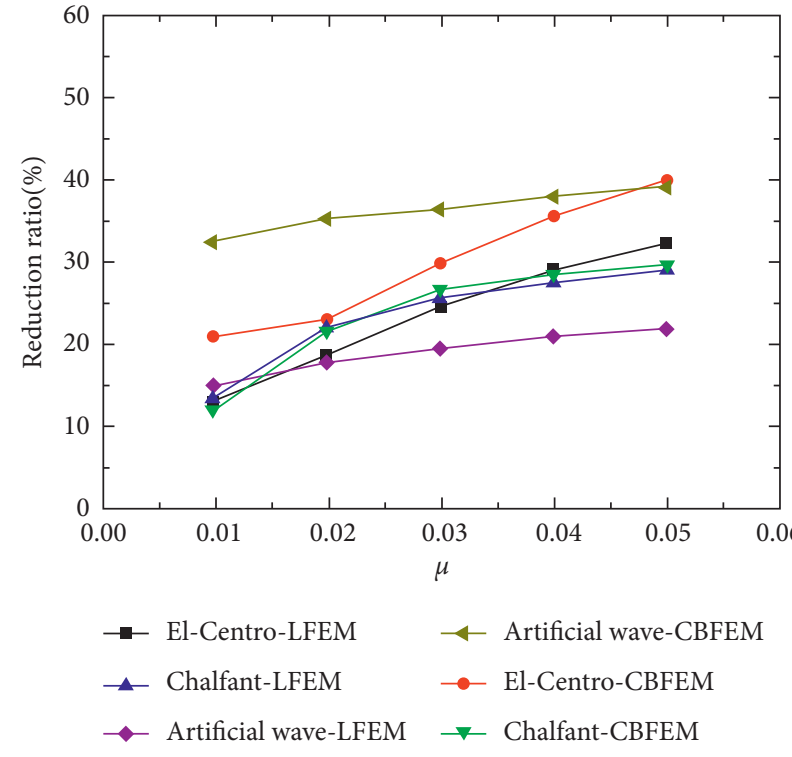

(d)

Figure 20: The reduction ratio of acceleration induced by bi-directional earthquakes. (a) Acceleration in fore-aft direction. (b) Acceleration in side-side direction. (c) Acceleration standard deviation in fore-aft direction. (d) Acceleration standard deviation in side-side direction.

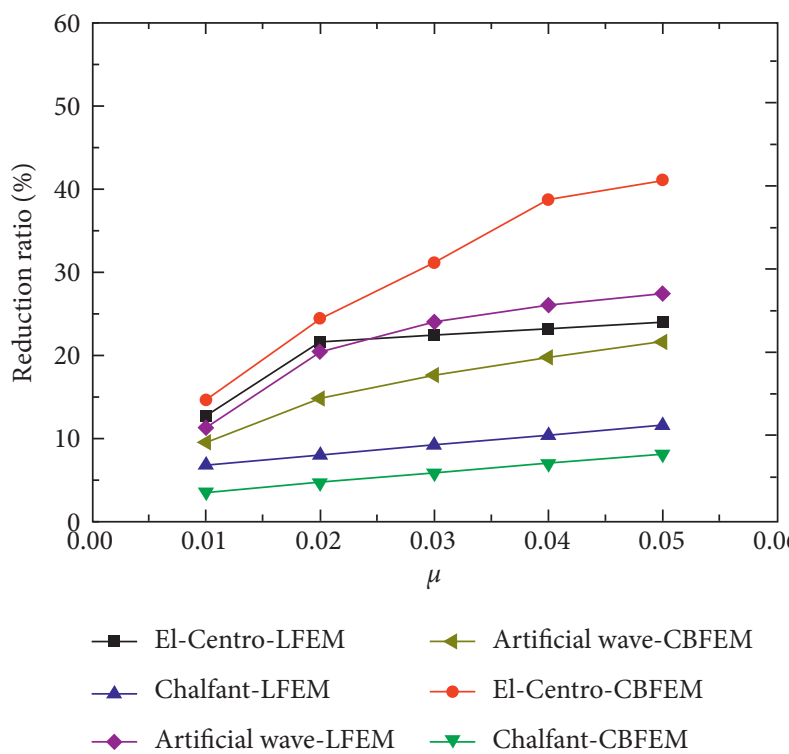

(a)

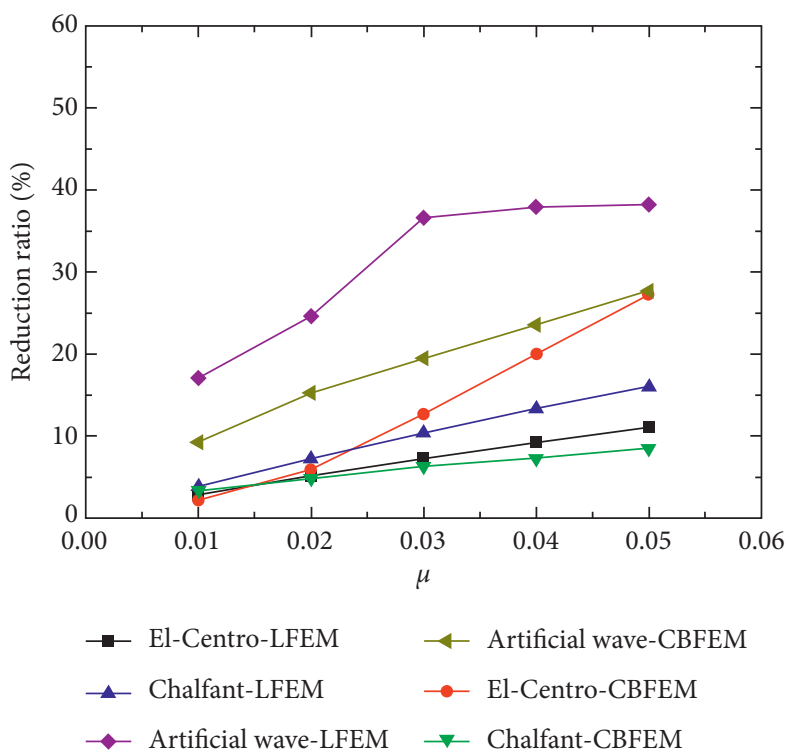

(b)

Figure 21: Continued. 


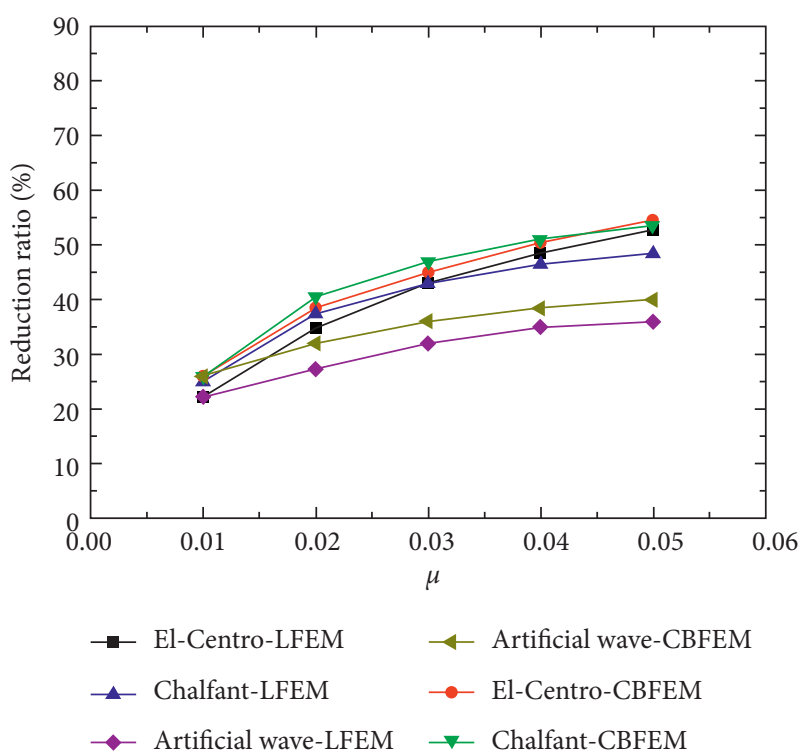

(c)

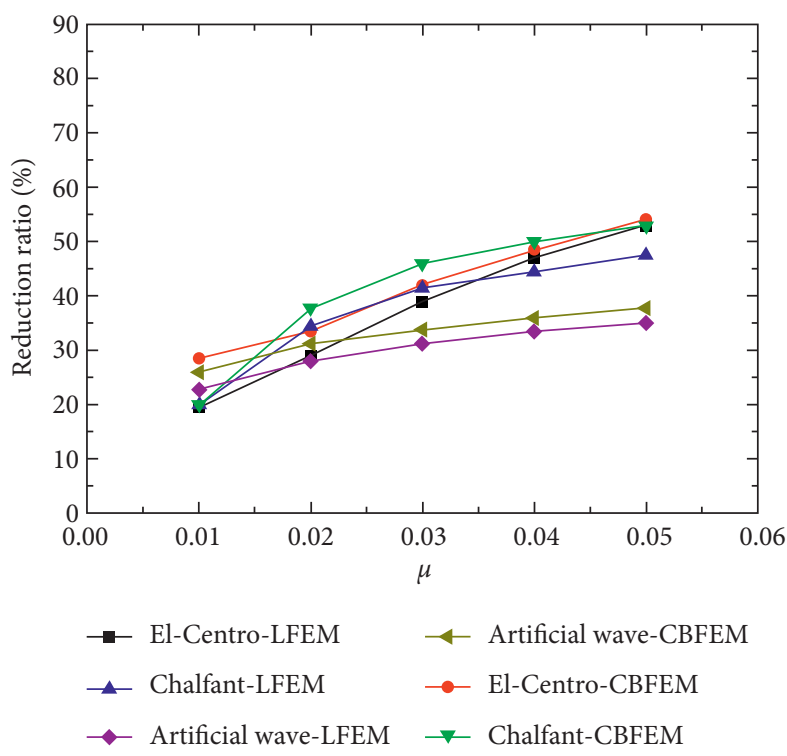

(d)

FIgURE 21: The reduction ratio of the bottom bending moments induced by bi-directional earthquakes. (a) The peak value in fore-aft direction. (b) The peak value in side-side direction. (c) The standard deviation in fore-aft direction. (d) The standard deviation in side-side direction.

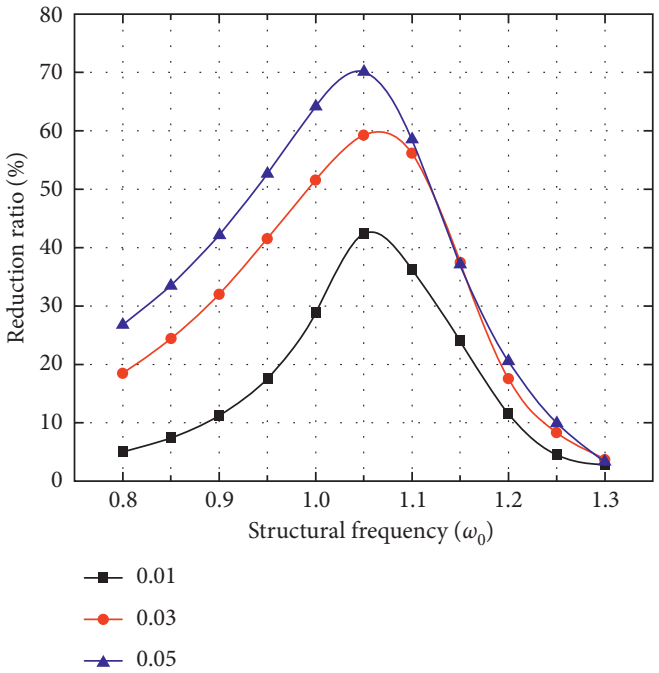

(a)

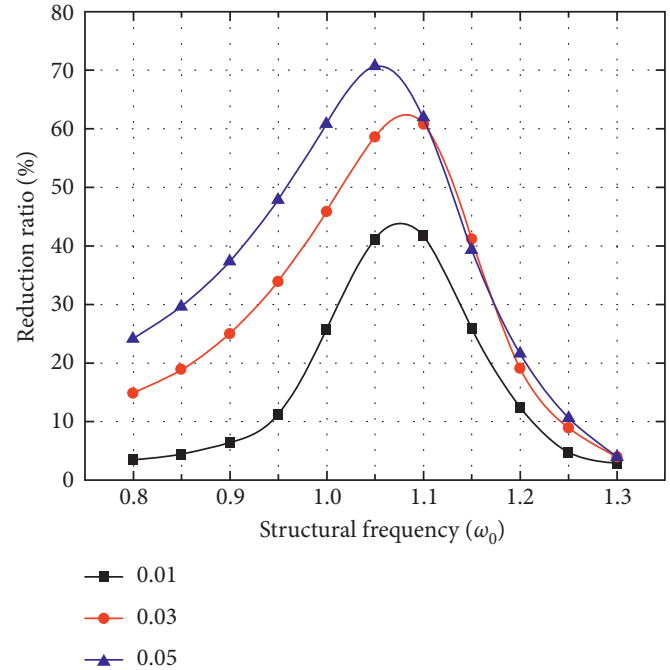

(b)

Figure 22: Continued. 


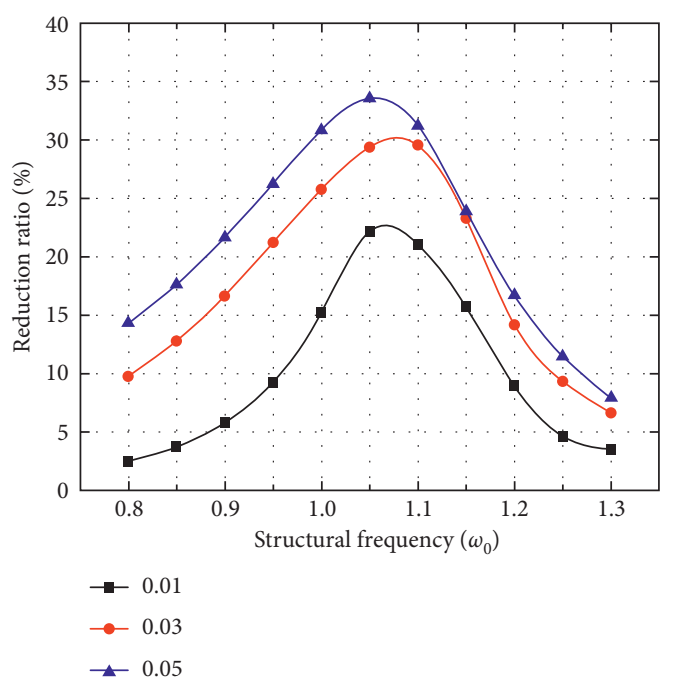

(c)

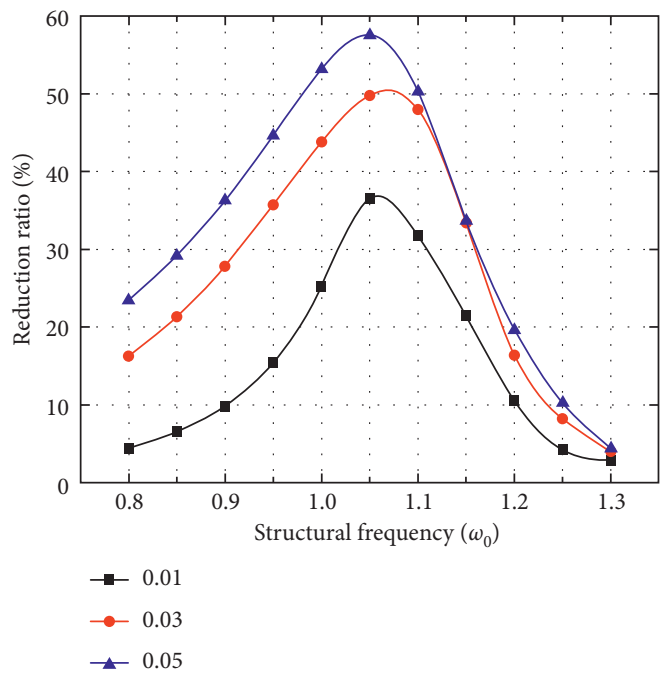

(e)

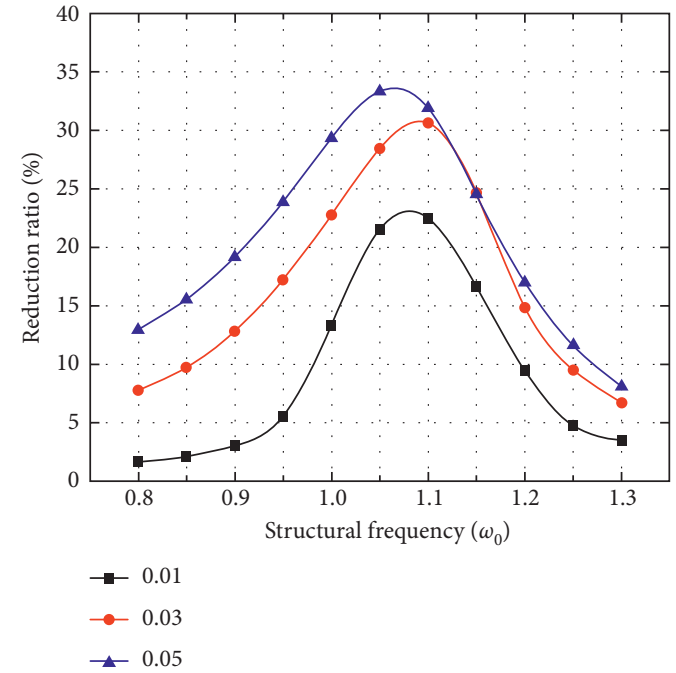

(d)

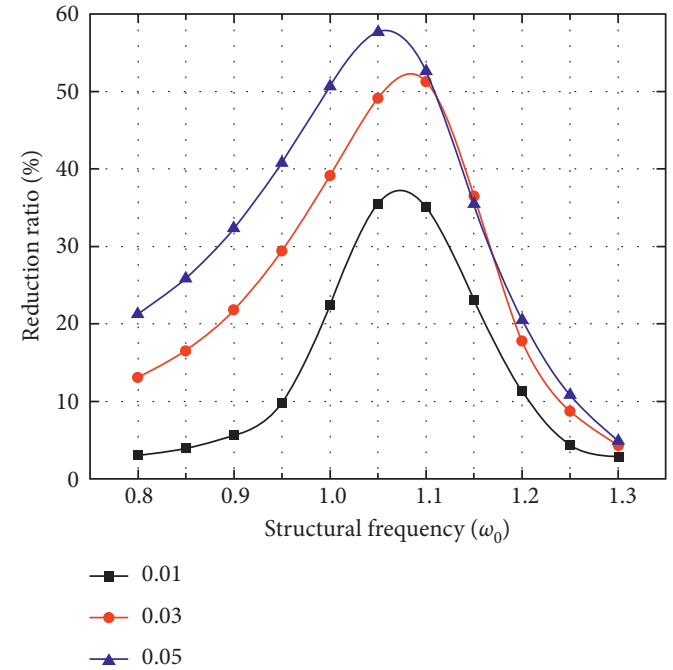

(f)

FIGURE 22: The reduction ratio of structural responses induced by bi-directional earthquakes. (a) Fore-aft direction displacement. (b) Sideside direction displacement. (c) Fore-aft direction acceleration. (d) Side-side direction acceleration. (e) Fore-aft direction moment. (f) Sideside direction moment.

calculated using the CBFEM is lower than those calculated using the LFEM due to the blade tower coupling effect.

\subsection{The Influence of Wind Turbine Frequency on the Response} Reduction. The natural frequency of the wind turbine is time-varying, which is influenced by many factors, including the centrifugal stiffening effect of the blade, ice, snow, and temperature. The BTMD might be mistuned due to the frequency variation. The mistuning effect would lead to the malfunction of the BTMD, even the amplification of structural responses. Therefore, the influence of frequency variation on the mitigation efficiency of the BTMD is investigated using the LFEM and CBFEM. The fundamental structural frequency varies from $0.8 \omega_{0}$ to $1.3 \omega_{0}$, where $\omega_{0}$ is the initial fundamental frequency of the wind turbine. Accordingly, the displacement, acceleration, and bending moment reduction ratios of the wind turbine with different mass ratios BTMD are shown in Figure 22.

The structural response reduction ratios increase with the increase of structural frequency before the structural frequency reaches $1.05 \omega_{0}$. The opposite situation applies to the situation that the structural frequency exceeds 1.05 $\omega_{0}$. The phenomenon is caused by the reason that the system wind turbine and TMD cannot resonate when the structural frequency is far from $\omega_{0}$, which causes smaller movement of the mass block. Generally, the BTMD can reduce effectively when the wind turbine frequency changed slightly. 


\section{Conclusions}

In this study, a BTMD is proposed to mitigate the seismic vibration of the wind turbine tower. Accordingly, the LFEM and CBFEM are used to investigate the vibration mitigation performance of the proposed BTMD. Afterward, the mitigation performances of the BTMD under uni- and bi-directional earthquakes are investigated. The displacement, acceleration, and bending moment of the wind turbine tower are analyzed in time-domain and frequency-domain. The following conclusions can be drawn from this study:

(1) The first two natural frequencies of the LFEM and CBFEM are similar to each other. However, the other natural frequencies of the LFEM are larger than that of the CBFEM due to the blade tower coupling effect. Meanwhile, the blade coupling effect is evident in the mode shape of the CBFEM. Accordingly, the reduction ratio calculated using the CBFEM is lower than those calculated using the LFEM. Hence, the coupling effect may have significant influences on the mitigation efficiency of the BTMD.

(2) The reduction ratios of the structural responses in two directions are similar to each other, which grow with the increase of the mass ratio. The proposed BTMD can significantly mitigate the peak values of the top displacement and bottom bending moment. However, it shows weak efficiency in controlling the peak acceleration, especially in the initial stage. Note that the BTMD can effectively depress the fatigue load of the wind turbines.

(3) The Fourier spectra of the displacement are mainly concentrated around the first natural frequency. However, the frequency peak of acceleration appears around the first two natural frequencies. The amplitude around the controlled frequency decreases significantly with the increase of the mass ratio. The mitigation efficiency of the BTMD would decrease with the structural frequency far away from the controlled frequency.

\section{Data Availability}

The finite element model, the responses data, and the code used to support the findings of this study are available from the corresponding author upon request.

\section{Conflicts of Interest}

The authors declare that there are no conflicts of interest regarding the publication of this paper.

\section{Acknowledgments}

This research was funded by the National Natural Science Foundation of China (grant numbers 51908266 and 51568041), the Hongliu Excellent Young Scholar Support Program of Lanzhou University of Technology, and the
Fund of International Research Based on Seismic Mitigation and Isolation of Gansu Province (grant number GII2018N04).

\section{References}

[1] C.-C. Lin, J.-M. Ueng, and T.-C. Huang, "Seismic response reduction of irregular buildings using passive tuned mass dampers," Engineering Structures, vol. 22, no. 5, pp. 513-524, 2000.

[2] C. Li, "Performance of multiple tuned mass dampers for attenuating undesirable oscillations of structures under the ground acceleration," Earthquake Engineering \& Structural Dynamics, vol. 29, no. 9, pp. 1405-1421, 2000.

[3] C. Xing, H. Wang, A. Li, and Y. Xu, "Study on wind-induced vibration control of a long-span cable-stayed bridge using TMD-type counterweight," Journal of Bridge Engineering, vol. 19, no. 1, pp. 141-148, 2014.

[4] J. Ou, X. Long, Q. S. Li, and Y. Q. Xiao, "Vibration control of steel jacket offshore platform structures with damping isolation systems," Engineering Structures, vol. 29, no. 7, pp. 1525-1538, 2007.

[5] H. N. Li and X. L. Ni, "Optimization of non-uniformly distributed multiple tuned mass damper," Journal of Sound and Vibration, vol. 308, no. 2, pp. 80-97, 2007.

[6] Z. Lu, X. Chen, D. Zhang, and K. Dai, "Experimental and analytical study on the performance of particle tuned mass dampers under seismic excitation," Earthquake Engineering \& Structural Dynamics, vol. 46, no. 5, pp. 697-714, 2017.

[7] J. C. H. Chang and T. T. Soong, "Structural control using active tuned mass dampers," Journal of the Engineering Mechanics Division, vol. 106, no. 6, pp. 1091-1098, 1980.

[8] X. Yan, Z. D. Xu, and Q. X. Shi, "Fuzzy neural network control algorithm for asymmetric building structure with active tuned mass damper," Journal of Vibration and Control, vol. 26, no. 21-22, 2020.

[9] M. D. Symans and M. C. Constantinou, "Semi-active control systems for seismic protection of structures: a state-of-the-art review," Engineering Structures, vol. 21, no. 6, pp. 469-487, 1999.

[10] T. Pinkaew and Y. Fujino, "Effectiveness of semi-active tuned mass dampers under harmonic excitation," Engineering Structures, vol. 23, no. 7, pp. 850-856, 2001.

[11] K. Karami, S. Manie, K. Ghafouri, and S. Nagarajaiah, "Nonlinear structural control using integrated DDA/ISMP and semi-active tuned mass damper," Engineering Structures, vol. 181, pp. 589-604, 2019.

[12] T. T. Soong and B. F. Spencer Jr., "Supplemental energy dissipation: state-of-the-art and state-of-the-practice," Engineering Structures, vol. 24, no. 3, pp. 243-259, 2002.

[13] H. Kim and H. Adeli, "Wind-induced motion control of 76story benchmark building using the hybrid damper-TLCD system," Journal of Structural Engineering, vol. 131, no. 12, pp. 1794-1802, 2005.

[14] G. M. Stewart and M. A. Lackner, "The impact of passive tuned mass dampers and wind-wave misalignment on offshore wind turbine loads," Engineering Structures, vol. 73, pp. 54-61, 2014.

[15] O. Altay, F. Taddei, C. Butenweg, and S. Klinkel, "Vibration mitigation of wind turbine towers with tuned mass dampers," in Wind Turbine Control and Monitoring, pp. 337-373, Springer, Cham, Switzerland, 2014.

[16] B. Zhao, H. Gao, Z. Wang, and Z. Lu, "Shaking table test on vibration control effects of a monopile offshore wind turbine 
with a tuned mass damper," Wind Energy, vol. 21, no. 12, pp. 1309-1328, 2018.

[17] S. Colwell and B. Basu, "Tuned liquid column dampers in offshore wind turbines for structural control," Engineering Structures, vol. 31, no. 2, pp. 358-368, 2009.

[18] T. Buckley, P. Watson, P. Cahill, V. Jaksic, and V. Pakrashi, "Mitigating the structural vibrations of wind turbines using tuned liquid column damper considering soil-structure interaction," Renewable Energy, vol. 120, pp. 322-341, 2018.

[19] A. Hemmati, E. Oterkus, and M. Khorasanchi, "Vibration suppression of offshore wind turbine foundations using tuned liquid column dampers and tuned mass dampers," Ocean Engineering, vol. 172, pp. 286-295, 2019.

[20] K. S. Dai, J. Z. Wang, R. F. Mao, Z. H. Xiang, and Z. Lu, "Wind tunnel test study on a new passive damper TL-PD," Earthquake Engineering and Engineering Vibration, vol. 01, no. 5, pp. 35-40, 2015, in Chinese.

[21] J. Chen, G. Zhan, and Y. Zhao, "Application of spherical tuned liquid damper in vibration control of wind turbine due to earthquake excitations," The Structural Design of Tall and Special Buildings, vol. 25, no. 10, pp. 431-443, 2016.

[22] Z. Zhang, A. Staino, B. Basu, and S. R. K. Nielsen, "Performance evaluation of full-scale tuned liquid dampers (TLDs) for vibration control of large wind turbines using real-time hybrid testing," Engineering Structures, vol. 126, pp. 417-431, 2016.

[23] C. Van der Woude and S. Narasimhan, "A study on vibration isolation for wind turbine structures," Engineering Structures, vol. 60, pp. 223-234, 2014.

[24] W. R. Li, J. Huang, and Y. F. Du, "Dynamic response analysis of wind turbines under long-period ground motions," Data Mining in Structural Dynamic Analysis, pp. 65-84, Springer, Singapore, 2019.

[25] H. Zuo, K. Bi, and H. Hao, "Using multiple tuned mass dampers to control offshore wind turbine vibrations under multiple hazards," Engineering Structures, vol. 141, pp. 303315, 2017.

[26] M. Hussan, M. S. Rahman, F. Sharmin, D. Kim, and J. Do, "Multiple tuned mass damper for multi-mode vibration reduction of offshore wind turbine under seismic excitation," Ocean Engineering, vol. 160, pp. 449-460, 2018.

[27] S. Gaur, S. Elias, T. Höbbel, V. A. Matsagar, and K. Thiele, "Tuned mass dampers in wind response control of wind turbine with soil-structure interaction," Soil Dynamics and Earthquake Engineering, vol. 132, Article ID 106071, 2020.

[28] Y. Hu, J. Wang, M. Z. Q. Chen, Z. Li, and Y. Sun, "Load mitigation for a barge-type floating offshore wind turbine via inerter-based passive structural control," Engineering Structures, vol. 177, pp. 198-209, 2018.

[29] R. Zhang, Z. Zhao, and K. Dai, "Seismic response mitigation of a wind turbine tower using a tuned parallel inerter mass system," Engineering Structures, vol. 180, pp. 29-39, 2019.

[30] M. L. Brodersen, A.-S. Bjørke, and J. Høgsberg, "Active tuned mass damper for damping of offshore wind turbine vibrations," Wind Energy, vol. 20, no. 5, pp. 783-796, 2017.

[31] C. Sun, "Semi-active control of monopile offshore wind turbines under multi-hazards," Mechanical Systems and Signal Processing, vol. 99, pp. 285-305, 2018.

[32] C. Sun and V. Jahangiri, "Bi-directional vibration control of offshore wind turbines using a 3D pendulum tuned mass damper," Mechanical Systems and Signal Processing, vol. 105, pp. 338-360, 2018.

[33] X. Tong, X. Zhao, and S. Zhao, "Load reduction of a monopile wind turbine tower using optimal tuned mass dampers,"
International Journal of Control, vol. 90, no. 7, pp. 1283-1298, 2017.

[34] M. Rahman, Z. C. Ong, W. T. Chong, S. Julai, and S. Y. Khoo, "Performance enhancement of wind turbine systems with vibration control: a review," Renewable and Sustainable Energy Reviews, vol. 51, pp. 43-54, 2015.

[35] H. R. Zuo, K. M. Bi, and H. Hao, "A state-of-the-art review on the vibration mitigation of wind turbines," Renewable and Sustainable Energy Reviews, vol. 121, Article ID 109710, 2020.

[36] N. Bazeos, G. D. Hatzigeorgiou, I. D. Hondros, H. Karabalis, and D. E. Beskos, "Static, seismic and stability analyses of a prototype wind turbine steel tower," Engineering Structures, vol. 24, no. 8, pp. 1015-1025, 2002.

[37] I. Lavassas, G. Nikolaidis, P. Zervas, E. Efthimiou, I. N. Doudoumis, and C. C. Baniotopoulos, "Analysis and design of the prototype of a steel 1-MW wind turbine tower," Engineering Structures, vol. 25, no. 8, pp. 1097-1106, 2003.

[38] R. Harrison, E. Hau, and H. Snel, Large Wind Turbines: Design and Economics, John Wiley and Sons, Ltd, New York, NY, USA, 2000.

[39] A. Banerjee, T. Chakraborty, V. Matsagar, and M. Achmus, "Dynamic analysis of an offshore wind turbine under random wind and wave excitation with soil-structure interaction and blade tower coupling," Soil Dynamics and Earthquake Engineering, vol. 125, Article ID 105699, 2019.

[40] International Electrotechnical Commission (IEC), Wind Turbines-Part 1: Design Requirements, International Electrotechnical Commission, Geneva, Switzerland, IEC 61400-1, 3rd edition, 2005.

[41] GB 50011-2010, Code for Seismic Design of Buildings, China Ministry of Construction, Beijing, China, 2016, in Chinese.

[42] T. Tao, H. Wang, and K. Zhao, "Efficient simulation of fully non-stationary random wind field based on reduced 2D hermite interpolation," Mechanical Systems and Signal Processing, vol. 150, Article ID 107265, 2021.

[43] T. Tao, H. Wang, L. Hu, and A. Kareem, "Error analysis of multivariate wind field simulated by interpolation-enhanced spectral representation method," Journal of Engineering Mechanics, vol. 146, no. 6, Article ID 04020049, 2020.

[44] T. Tao and H. Wang, "Modelling of longitudinal evolutionary power spectral density of typhoon winds considering highfrequency subrange," Journal of Wind Engineering and Industrial Aerodynamics, vol. 193, Article ID 103957, 2019.

[45] T. Tao, H. Wang, C. Yao, X. He, and A. Kareem, "Buffeting analysis of long-span bridges under typhoon winds with timevarying spectra and coherences," Journal of Structural Engineering, vol. 146, no. 2, Article ID 04020255, 2018.

[46] D. Witcher, "Seismic analysis of wind turbines in the time domain," Wind Energy, vol. 8, no. 1, pp. 81-91, 2005.

[47] D. H. Kim, S. G. Lee, and I. K. Lee, "Seismic fragility analysis of $5 \mathrm{MW}$ offshore wind turbine," Renewable Energy, vol. 65, pp. 250-256, 2014. 